MECEIVED

DEC 051995

OSTI

MWIR-1995

DOE National Mixed and TRU Waste Database Users Guide

Radioactive Waste Technical Support Program

November 1995 


\section{DISCLAIMER}

Portions of this document may be illegible in electronic image products. Images are produced from the best available original document. 


\title{
MWIR-1995 \\ DOE National Mixed and TRU Waste Database Users Guide
}

\author{
Radioactive Waste Technical \\ Support Program
}

Published November 1995

\section{Idaho National Engineering Laboratory Lockheed Idaho Technologies Company Idaho Falls, Idaho 83415}

Prepared for the

U.S. Department of Energy

Assistant Secretary for Environmental Management

Under DOE Idaho Operations Office

Contract DE-AC07-94ID13223 


\section{CONTENTS}

1. INTRODUCTION $\ldots \ldots \ldots \ldots \ldots \ldots \ldots \ldots \ldots \ldots \ldots \ldots \ldots \ldots \ldots$

2. COMPUTER SYSTEM REQUIREMENTS $\ldots \ldots \ldots \ldots \ldots \ldots \ldots \ldots \ldots \ldots$

2.1 Hardware/Software Requirements $\ldots \ldots \ldots \ldots \ldots \ldots \ldots \ldots \ldots \ldots \ldots \ldots \ldots$

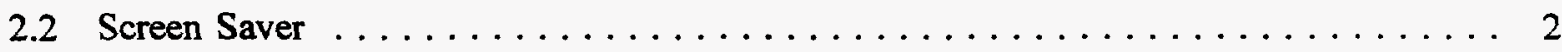

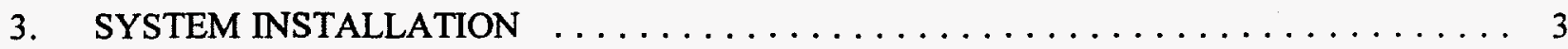

3.1 System and Data Diskettes $\ldots \ldots \ldots \ldots \ldots \ldots \ldots \ldots \ldots \ldots \ldots$

3.1.1 Loading the MWIR-1995 System Diskettes . . . . . . . . . . . . 3

3.1.2 Loading the MWIR-1995 Data Diskettes $\ldots \ldots \ldots \ldots \ldots \ldots \ldots \ldots$

3.2 Network Connection $\ldots \ldots \ldots \ldots \ldots \ldots \ldots \ldots \ldots \ldots \ldots \ldots \ldots \ldots$

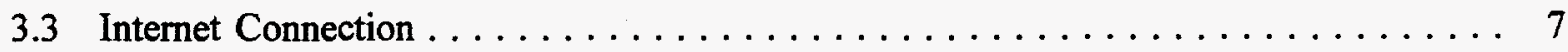

3.3.1 Transfer of MWIR-1995 Files . . . . . . . . . . . . . . . 7

3.3.2 Loading the MWIR-1995 System $\ldots \ldots \ldots \ldots \ldots \ldots \ldots \ldots \ldots$

3.3.3 Loading the MWIR-1995 Data $\ldots \ldots \ldots \ldots \ldots \ldots \ldots \ldots \ldots \ldots$

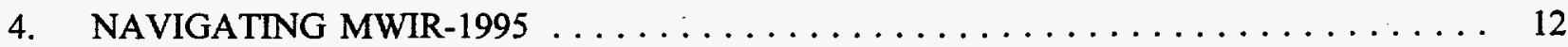

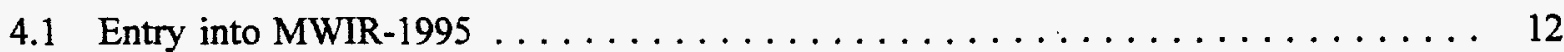

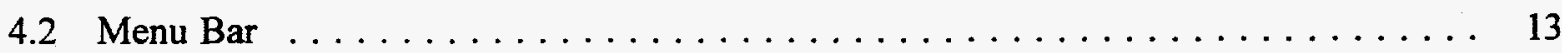

4.3 Tool Bar $\ldots \ldots \ldots \ldots \ldots \ldots \ldots \ldots \ldots \ldots \ldots \ldots \ldots \ldots \ldots \ldots \ldots$

4.4 Screens and Forms $\ldots \ldots \ldots \ldots \ldots \ldots \ldots \ldots \ldots \ldots \ldots \ldots \ldots$

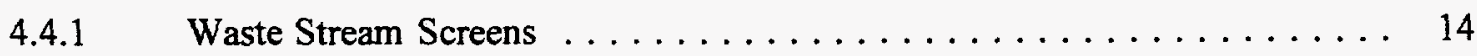

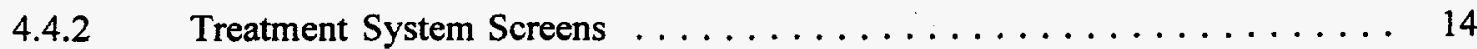

$4.4 .3 \quad$ Forms $\ldots \ldots \ldots \ldots \ldots \ldots \ldots \ldots \ldots \ldots \ldots \ldots$

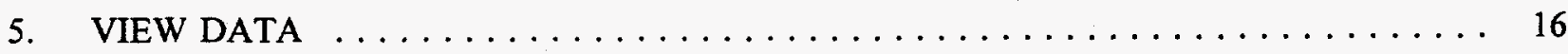

5.1 View Survey $\ldots \ldots \ldots \ldots \ldots \ldots \ldots \ldots \ldots \ldots \ldots \ldots \ldots \ldots \ldots$

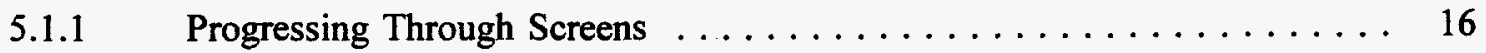

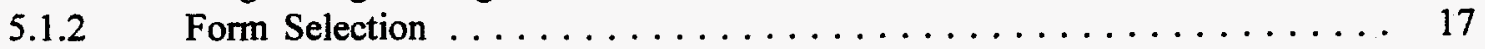

5.1.3 Maneuvering Inside Forms $\ldots \ldots \ldots \ldots \ldots \ldots \ldots \ldots \ldots \ldots$

6. QUERIES ................................. 19 
6.1 Form Query .............................. 19

6.1.1 How to Use Form Query $\ldots \ldots \ldots \ldots \ldots \ldots \ldots \ldots \ldots$

6.1.2 Form Query Examples ..................... 20

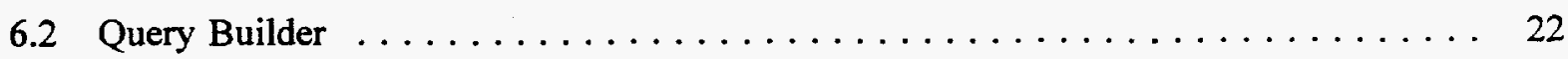

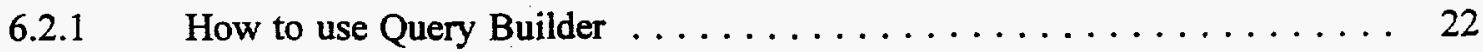

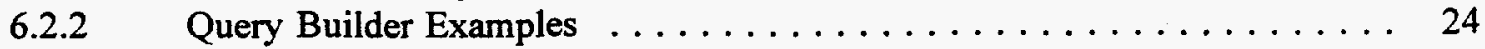

7. PRINTING SURVEYS AND STANDARDIZED REPORTS $\ldots \ldots \ldots \ldots \ldots \ldots \ldots$

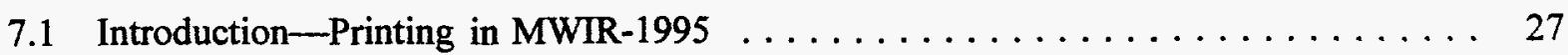

7.2 Setting Up The Printer $\ldots \ldots \ldots \ldots \ldots \ldots \ldots \ldots \ldots \ldots \ldots \ldots \ldots \ldots$

7.3 Printing a Waste Stream or Treatment Survey $\ldots \ldots \ldots \ldots \ldots \ldots \ldots$

7.3.1 Printing a Complete Survey . . . . . . . . . . . . . . 29

7.3.2 Printing a Short Version Survey .................... 29

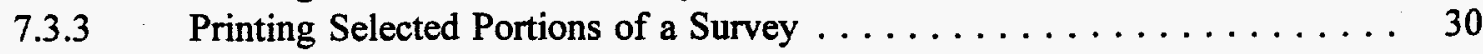

7.3.4 Printing Several Surveys $\ldots \ldots \ldots \ldots \ldots \ldots \ldots \ldots \ldots \ldots \ldots \ldots \ldots$

7.3.4.1 Selecting Several Surveys . . . . . . . . . . . . . . 31

7.3.4.2 Viewing a Specific List of Surveys $\ldots \ldots \ldots \ldots \ldots \ldots \ldots \ldots \ldots$

7.4 Developing and Printing Standardized Reports $\ldots \ldots \ldots \ldots \ldots \ldots \ldots$

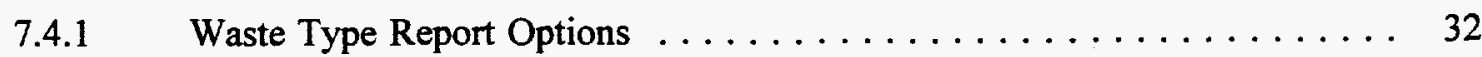

7.4.2 Waste Stream Report Options . . . . . . . . . . . . . . . 34

7.4.3 Treatment System Summary Report Options .............. 37

7.5 Printing a MWIR-1995 Data Dictionary $\ldots \ldots \ldots \ldots \ldots \ldots \ldots \ldots$

8. EDITING/UPDATING DATA $\ldots \ldots \ldots \ldots \ldots \ldots \ldots \ldots \ldots \ldots \ldots$

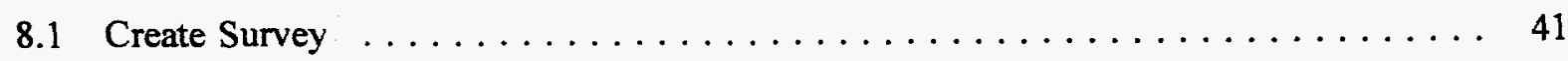

8.2 Delete Survey $\ldots \ldots \ldots \ldots \ldots \ldots \ldots \ldots \ldots \ldots \ldots \ldots \ldots \ldots \ldots$

8.3 Duplicate Survey $\ldots \ldots \ldots \ldots \ldots \ldots \ldots \ldots \ldots \ldots \ldots \ldots \ldots \ldots \ldots$

8.4 Edit Survey $\ldots \ldots \ldots \ldots \ldots \ldots \ldots \ldots \ldots \ldots \ldots \ldots \ldots \ldots \ldots \ldots$

8.5 Spell Check $\ldots \ldots \ldots \ldots \ldots \ldots \ldots \ldots \ldots \ldots \ldots \ldots \ldots \ldots \ldots \ldots$

9. MWIR-1995 SUPPORT $\ldots \ldots \ldots \ldots \ldots \ldots \ldots \ldots \ldots \ldots \ldots \ldots \ldots \ldots$

9.1 Technical Support $\ldots \ldots \ldots \ldots \ldots \ldots \ldots \ldots \ldots \ldots \ldots \ldots \ldots \ldots \ldots$ 
Appendix A-MWTR-1995 Menu Bar . . . . . . . . . . . . . . . . A-1

Appendix B-MWIR-1995 Tool Bar $\ldots \ldots \ldots \ldots \ldots \ldots \ldots \ldots \ldots \ldots \ldots \ldots \ldots$

Appendix C-MWIR-1995 Look-Up Tables $\ldots \ldots \ldots \ldots \ldots \ldots \ldots \ldots \ldots \ldots \ldots$

\section{LIST OF FIGURES}

Figure $4-1$. Main Menu screen $\ldots \ldots \ldots \ldots \ldots \ldots \ldots \ldots \ldots \ldots \ldots \ldots \ldots \ldots \ldots$

Figure 4-2. Main Menu screen (read only) $\ldots \ldots \ldots \ldots \ldots \ldots \ldots \ldots \ldots \ldots \ldots \ldots$

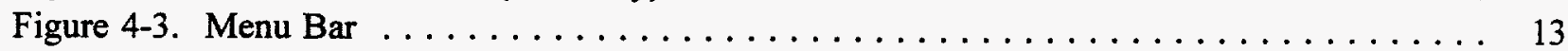

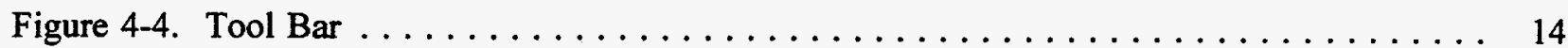

Figure 4-5. Record Select Bar $\ldots \ldots \ldots \ldots \ldots \ldots \ldots \ldots \ldots \ldots \ldots \ldots \ldots \ldots$

Figure $5-1$. System Forms dialog box $\ldots \ldots \ldots \ldots \ldots \ldots \ldots \ldots \ldots \ldots \ldots \ldots$

Figure 6-1. Query Builder select tables dialog box $\ldots \ldots \ldots \ldots \ldots \ldots \ldots \ldots \ldots$

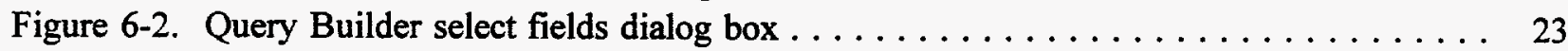

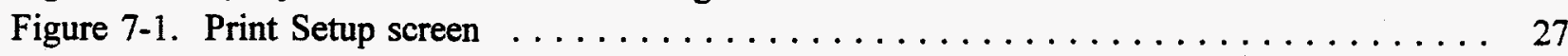

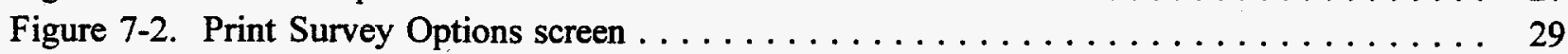

Figure 7-3. Waste Type Report Options screen $\ldots \ldots \ldots \ldots \ldots \ldots \ldots \ldots \ldots \ldots$

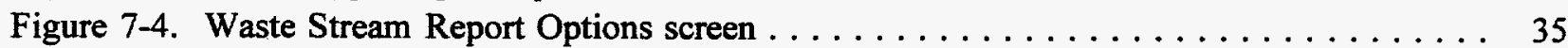

Figure 7-5. Treatment System Summary Report Options screen $\ldots \ldots \ldots \ldots \ldots \ldots$

Figure A-1. Menu Bar . . . . . . . . . . . . . . . . . . . . .

Figure B-1. Tool Bar . . . . . . . . . . . . . . . . . . .

\section{DISCLAIMER}

This report was prepared as an account of work sponsored by an agency of the United States Government. Neither the United States Government nor any agency thereof, nor any of their employees, makes any warranty, express or implied, or assumes any legal liability or responsibility for the accuracy, completeness, or usefulness of any information, apparatus, product, or process disclosed, or represents that its use would not infringe privately owned rights. Reference herein to any specific commercial product, process, or service by trade name, trademark, manufacturer, or otherwise does not necessarily constitute or imply its endorsement, recommendation, or favoring by the United States Government or any agency thereof. The views and opinions of authors expressed herein do not necessarily state or reflect those of the United States Government or any agency thereof. 


\section{INTRODUCTION}

The Department of Energy (DOE) National 1995 Mixed Waste Inventory Report (MWIR-1995) Database Users Guide provides information on computer system requirements and describes installation, operation, and navigation through the database.

The MWIR-1995 database contains a detailed, nationwide compilation of information on DOE mixed waste streams and treatment systems. In addition, the 1995 version includes data on nonmixed, transuranic (TRU) waste streams. These were added to the data set as a result of coordination of the 1995 update with the National Transuranic Program Office's (NTPO's) data needs to support the Waste Isolation Pilot Plant (WIPP) TRU Waste Baseline Inventory Report (WTWBIR). However, the information on the TRU waste streams is limited to that associated with the core mixed waste data requirements. The additional, non-core data on TRU streams collected specifically to support the WTWBIR is not included in the MWIR-1995 database.

With respect to both the mixed and TRU waste stream data, the data set addresses "stored" streams. In this instance, "stored" streams are defined as (a) streams currently in storage at both EM30 and EM-40 sites and (b) streams that have yet to be generated but are anticipated within the next five years from sources other than environmental restoration and decontamination and decommissioning (ER/D\&D) activities. Information on future ER/D\&D streams is maintained in the EM-40 core database. The MWIR-1995 database also contains limited information for both waste streams and treatment systems that have been removed or deleted since the 1994 MWIR. Data on these is maintained only through Section 2, Waste Stream Identification/Tracking/Source, to document the reason for removal from the data set.

The main body of this user's guide provides information on navigating the system, performing queries, producing reports, and editing the data. The appendices provide additional detailed information describing the Menu Bar and Tool Bar selections and data element look-up tables within MWIR-1995. If a question or problem is encountered when operating MWIR-1995 that cannot be readily resolved by using this guide, technical support is available, as identified in Section 9. 


\section{COMPUTER SYSTEM REQUIREMENTS}

MWIR-1995 is a Windows stand-alone application based on Microsoft Access 2.0. The Microsoft Access software is not required to run MWIR-1995. The installation process identified in Section 3, System Installation, automatically creates a program group and associated icons to allow running MWIR-1995 within the Windows environment.

\subsection{Hardware/Software Requirements}

To allow execution of MWIR-1995, the user's personal computer must have:

- 486 processor (or higher)

- 8 megabytes of memory (or greater)

- 30 megabytes of free hard disk space

- $\quad$ Microsoft Windows 3.1 or equivalent.

\subsection{Screen Saver}

A screen saver is provided when MWIR-1995 is installed. The screen saver is loaded to the default directory (C:IMTI) and is named decay.scr. If assistance is needed to activate the screen saver, technical support is available, as identified in Section 9. 


\section{SYSTEM INSTALLATION}

The installation process creates a program group and associated icons for MWIR-1995. Three methods can be used to access MWIR-1995 data: (a) load the MWIR-1995 system and data using the System and Data Diskettes; (b) access the MWIR-1995 system and data using a network connection; or (c) load the MWIR-1995 system and data using files downloaded from an Internet site.

NOTE 1: If you have a version of MITI 95 loaded on your computer, the MWIR-1995 setup routine will replace the older system with the newer MWIR-1995 system. Old data files can be attached using MWIR-1995.

NOTE 2: Loading the MWIR-1995 data files will not interfere with any data files that are currently loaded on your computer (as long as none of them are labeled MWIRREAD.MDB).

\subsection{System and Data Diskettes}

The system and data files are contained on a set of ten diskettes, five system diskettes and five data diskettes. Both the system and data diskette packages are installed using a setup routine, which is described in the following subsections.

\subsubsection{Loading the MWIR-1995 System Diskettes}

1. Start up your computer and make sure you are in Windows.

2. Close all Windows applications (e.g., WordPerfect, Lotus 1-2-3, or other programs).

3. Insert MWIR-1995 system disk \#1 into your computer (it is assumed that the A: drive uses $3.5^{\prime \prime}$ diskettes).

4. From the Windows Program Manager select File.

5. From the File menu select $\underline{\text { Run... }}$

6. A dialog box will appear that contains a location for entering the Command Line:

7. Type A:setup as the command line and select $\mathbf{O K}$.

This action will activate the Microsoft Access setup program. Follow the instructions that appear on the screen.

The setup program will:

- Create a directory on the C: drive called MITI

- Install required files into the C:IMITI directory 
- Install required files into the Windows system directory

- Create a new program group called MITI 95

- Create an MWIR-1995 icon, a data disk icon, a compact/repair miti_sys.mdb icon, a compact/repair miti95.mdb icon, and a compact/repair data_dsk.mdb icon; it will load these icons into the MITI 95 program group.

8. A MITI 95 Setup dialog box will appear with the message, starting MITI 95 setup...

9. A MITI 95 Setup dialog box will appear with a Welcome message; select OK or press enter.

10. A dialog box will appear with the message, setup is searching for installed components...

11. A dialog box will appear that allows selecting the destination directory for MITI 95; the default value is "C:LMTI"; select OK or press enter to accept the default value.

12. A dialog box will appear with the message, setup is searching for installed components...

13. A dialog box will appear that initiates the actual installation of MWIR-1995; the message will be, "begin installation by clicking the large button"; press the large button with the computer on it or press enter.

14. A dialog box will appear that allows identification of the program group that MWIR-1995 will be connected to; the default value is MITI 95; select Continue or press enter to accept the default value.

15. A dialog box will appear with the message, setup is checking for necessary disk space...

16. Once sufficient hard drive space is verified, another dialog box will appear indicating that disk 1 is being loaded and the destination files currently being transferred; the status box is the percent of the total system loading process that is complete.

17. When disk 1 is loaded, the following message will appear: please insert the disk labeled 'Disk 2' into drive A:; insert system disk \#2 into drive A: and select $\mathrm{OK}$ or press enter.

18. A dialog box will appear indicating that disk 2 is being loaded and the destination files currently being transferred; the status box is the percent of the total system loading process that is complete.

19. When disk 2 is loaded, the following message will appear: please insert the disk labeled 'Disk 3' into drive A:; insert system disk \#3 into drive A: and select OK or press enter. 
20. A dialog box will appear indicating that Disk 3 is being loaded and the destination files currently being transferred; the status box is the percent of the total system loading process that is complete.

21. When disk 3 is loaded, the following message will appear: please insert the disk labeled 'Disk 4' into drive A:; insert system disk \#4 into drive A: and select OK or press enter.

22. A dialog box will appear indicating that disk 4 is being loaded and the destination files currently being transferred; the status box is the percent of the total system loading process that is complete.

23. When disk 4 is loaded, the following message will appear: please insert the disk labeled 'Disk 5' into drive A:; insert system disk \#5 into drive A: and select OK or press enter.

24. A dialog box will appear indicating that Disk 5 is being loaded and the destination files currently being transferred; the status box is the percent of the total system loading process that is complete.

25. When the loading status reaches 100 percent, a dialog box will appear with the message, setup is updating your system...

26. Once your system has been updated, the following message will appear: MITI 95 setup was completed successfully; select $\mathrm{OK}$ or press enter and the setup program will return to Windows; this will display the new MITI 95 program group containing the new icons.

\subsubsection{Loading the MWIR-1995 Data Diskettes}

1. Start up your computer and make sure you are in Windows.

2. Close all Windows applications (e.g., WordPerfect, Lotus 1-2-3, or other programs).

3. Insert MWIR-1995 data disk \#1 into your computer (it is assumed that the A: drive uses $3.5^{\prime \prime}$ diskettes).

4. From the Windows Program Manager select File.

5. From the File menu select $\underline{\text { Run... }}$

6. A dialog box will appear that contains a location for entering the Command Line:

7. Type A:setup as the command line and select $\mathbf{O K}$; this will run a setup routine very similar to that used when loading the data system.

8. A MITI (MWIR) Read Only Data Setup dialog box will appear with the message, starting MITI (MWIR) read only data setup... 
9. A MITI (MWIR) Read Only Data Setup dialog box will appear with a welcome message; select $\mathrm{OK}$ or press enter.

10. A dialog box will appear with the message, setup is searching for installed components...

11. A dialog box will appear that allows selecting the destination directory for MITI (MWIR) Read Only Data; the default value is "C:MMTI"; select OK or press enter to accept the default value.

12. A dialog box will appear with the message, setup is searching for installed components...

13. A dialog box will appear that initiates the actual installation of MITI (MWIR) Read Only Data; the message will be, "begin the installation by clicking the large button"; press the large button with the computer on it or press enter.

14. A dialog box will appear with the message, setup is checking for necessary disk space...

15. Once sufficient hard drive space is verified, another dialog box will appear indicating that disk 1 is being loaded and the files currently being transferred; the status box is the percent of the total data loading process that is complete.

16. When disk 1 is loaded, the following message will appear: please insert disk labeled 'Disk 2' into Drive A:; insert data disk \#2 into drive A: and select OK or press enter.

17. A dialog box will appear indicating that disk 2 is being loaded and the files currently being transferred; the status box is the percent of the total data loading process that is complete.

18. When disk 2 is loaded, the following message will appear: please insert disk labeled 'Disk 3' into drive A:; insert data disk \#3 into drive $A$ : and select $O K$ or press enter.

19. A dialog box will appear indicating that Disk 3 is being loaded and the files currently being transferred; the status box is the percent of the total data loading process that is complete.

20. When disk 3 is loaded, the following message will appear: please insert disk labeled 'Disk 4' into drive A:; insert data disk \#4 into drive A: and select $O K$ or press enter.

21. A dialog box will appear indicating that Disk 4 is being loaded and the files currently being transferred; the status box is the percent of the total data loading process that is complete.

22. When disk 4 is loaded, the following message will appear: please insert disk labeled 'Disk 5' into drive A:; insert data disk \#5 into drive A: and select $O K$ or press enter.

23. A dialog box will appear indicating that Disk 5 is being loaded and the files currently being transferred; the status box is the percent of the total data loading process that is complete.

24. When the loading status reaches 100 percent, a dialog box will appear with the message, setup is updating your system... 
25. Once your system has been updated, another message will appear, MITI (MWIR) read only data setup was completed successfully; select $O K$ or press enter and the setup program will return to the MITI 95 program group in Windows.

26. At this point, MWIR-1995 can be entered by double clicking on the MWIR 1995 icon in the MITI 95 program group (see Section 4, Navigating MWIR-1995).

\subsection{Network Connection}

Information on accessing MWIR-1995 using a network connection has not been developed. Contact Technical Support (see Section 9) if you have questions on network connections.

\subsection{Internet Connection}

The system files and the data files are represented as two self extracting files on an internet site. A readme file also resides on the internet site. The readme file is this user guide. These files can be downloaded to a PC and converted to a set of system files and a set of data files. MWIR-1995 is then installed using these files and the following loading procedure. The specific internet site(s) that will contain the MWIR-1995 files have not been confirmed. Contact Technical Support if you have questions on Internet Sites.

\subsubsection{Transfer of MWIR-1995 Files}

The installation procedure for MWIR-1995 requires that the necessary system and data files be in unique directories. Installation of these files is then executed from the windows file menu. This section covers the creation of the necessary directories, transfer of the correct files into these directories, and installation of MWIR-1995 from these directories.

1. Setup a temporary directory on your hard drive. Label this directory MWIR1995. This is the directory to which the MWIR System file will be transferred.

2. Setup a temporary directory on your hard drive. Label this directory MWIRREAD. This is the directory to which the MWIR Data file will be transferred.

3. Using FTP software of your choice access the FTP site that has the MWIR-1995 System file (MWIR1995.EXE).

4. Transfer the file named MWIR1995.EXE into your directory named MWIR1995 (the path should be C:(MWIR1995).

5. Using FTP software of your choice access the FTP site that has the MWIR-1995 Data file (MWIRREAD.EXE).

6. Transfer the file named MWIRREAD.EXE into your directory named MWIRREAD (the path should be C:IMWIRREAD). 
7. The MWIR-1995 system files can be extracted in several ways. The following is one of those processes:

- Using the windows file manager, select the directory that contains the MWIR-1995 system files (C:IMWIR1995).

- Double click the file named MWIR1995.EXE.

- This will cause the files contained in MWIR1995.EXE to self extract into the same directory where MWIR1995.EXE is located.

- Refresh the file manager screen to verify that files were extracted. The file MWIR1995.EXE can now be deleted to conserve hard drive memory.

8. The MWIR-1995 data files can be extracted in several ways. The following is one of those processes:

- Using the windows file manager, select the directory that contains the MWIR-1995 data files (C:IMWIRREAD).

- Double click the file named MWIRREAD.EXE.

- This will cause the files contained in MWIRREAD.EXE to self extract into the same directory where MWIRREAD.EXE is located.

- Refresh the file manager screen to verify that files were extracted. The file MWIRREAD.EXE can now be deleted to conserve hard drive memory.

9. Upon completion of these steps the necessary files will be available to install MWIR-1995 to your PC.

\subsubsection{Loading the MWIR-1995 System}

1. Start up your computer and make sure you are in windows.

2. Make sure that no applications are running under windows (i.e., WordPerfect, Lotus 1-2-3, etc.)

3. From the windows Program Manager select File

4. From the File menu select $\underline{\text { Run... }}$

5. A dialog box will appear that contains a location for entering the Command Line:.

6. Type C:mwir1995/setup as the command line and select OK. 
This action will activate the Microsoft Access setup program. Follow the instructions that appear on the screen.

The setup program will:

- Create a directory on the C: drive called MITI.

- Install necessary files into the C:IMITI directory.

- Install necessary files into the WINDOWS system directory.

- $\quad$ Create a new program group called MITI 95.

- Create a MWIR-1995 icon, a Data Disk icon, a Compact/Repair miti_sys.mdb icon, a Compact/Repair miti95.mdb icon, and a Compact/Repair data_dsk.mdb icon and will load them into the MITI 95 program group.

7. A MITI 95 Setup dialog box will appear with the message, Starting MITI 95 Setup...

8. A MITI 95 Setup dialog box will appear with a Welcome message. Select OK or press enter.

9. A dialog box will appear with the message, Setup is searching for installed components...

10. A dialog box will appear that allows selecting the destination directory for MITI 95 . The default value is "C:IMITI". Select OK or press enter to accept the default value.

11. A dialog box will appear with the message, Setup is searching for installed components...

12. A dialog box will appear that initiates the actual installation of MWIR-1995. The message will be, "Begin installation by clicking the large button". Press the large button with the computer on it or press enter.

13. A dialog box will appear that allows the identification of the program group that MWIR-

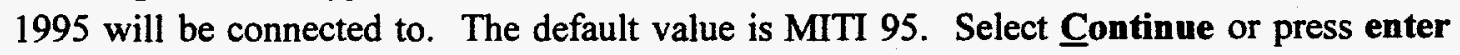
to accept the default value.

14. A dialog box will appear with the message, Setup is checking for necessary disk space...

15. Once sufficient hard drive space is verified, another dialog box will appear indicating that Disk 1 is being loaded and the destination files currently being transferred. The status box is the percent of the total system loading process that is complete.

16. When the loading status reaches 100 percent, a dialog box will appear with the message, Setup is updating your system... 
17. Once your system has been updated, another message will appear, MITI 95 Setup was completed successfully. Select $\mathrm{OK}$ or press enter and the setup program will return to Windows. This will display the new MITI 95 program group containing the new icons.

18. The temporary directory C:LMWIR1995 and its contents can now be deleted to conserve hard drive memory. All necessary system files have been decompressed and loaded to the C:IMITI directory.

\subsubsection{Loading the MWIR-1995 Data}

1. Start up your computer and make sure you are in windows.

2. Make sure that no applications are running under windows (i.e., WordPerfect, Lotus 1-2-3, etc.)

3. From the windows Program Manager select File

4. From the File menu select Run...

5. A dialog box will appear that contains a location for entering the Command Line:

6. Type C:Imwirreadisetup as the command line and select $\mathbf{O K}$. This will run a setup routine very similar to that used when loading the data system.

7. A MITI (MWIR) Read Only Data Setup dialog box will appear with the message, Starting MITI (MWIR) Read Only Data Setup...

8. A MITI (MWIR) Read Only Data Setup dialog box will appear with a Welcome message. Select $\mathbf{O K}$ or press enter.

9. A dialog box will appear with the message, Setup is searching for installed components...

10. A dialog box will appear that allows selecting the destination directory for MITI (MWIR) Read Only Data. The default value is "C:MITI". Select OK or press enter to accept the default value.

11. A dialog box will appear with the message, Setup is searching for installed components...

12. A dialog box will appear that initiates the actual installation of MITI (MWIR) Read Only Data. The message will be, "Begin the installation by clicking the large button". Press the large button with the computer on it or press enter.

13. A dialog box will appear with the message, Setup is checking for necessary disk space...

14. Once sufficient hard drive space is verified, another dialog box will appear indicating that Disk 1 is being loaded and the files currently being transferred. The status box is the percent of the total data loading process that is complete. 
15. When the loading status reaches 100 percent, a dialog box will appear with the message, Setup is updating your system...

16. Once your system has been updated, another message will appear, MITI (MWIR) Read Only Data Setup was completed successfully. Select OK or press enter and the setup program will return to the MITI 95 program group in Windows.

17. The temporary directory C:IMWIRREAD and its contents can now be deleted to conserve hard drive memory. All necessary system files have been decompressed and loaded to the C:IMITI directory.

18. At this point MWIR-1995 can be entered by double clicking on the MWIR 1995 icon in the MITI 95 program group (See Section 4, Navigating MWIR-1995). 


\section{NAVIGATING MWIR-1995}

\subsection{Entry into MWIR-1995}

To access the MWIR-1995 database, the user must perform the following steps:

1. Access Windows.

2. Select the program group that contains the MWIR-1995 icon (the default program group is MITI 95).

3. Double click on the MWIR 1995 icon; several screens will appear:

- The first screen is the Introduction to MITI screen

- The second screen is the Department of Energy (DOE) logo

- The third screen is the MITI Main Menu (Main Menu)(Figure 4-1).

NOTE: If this is the first time entering MWIR-1995 since loading the system and data, the above sequence of screens may be interrupted by a screen with the title, Where is MITI95.MDB?. This is actually the Attach Data screen under the File option from the Menu Bar and the message is simply telling the user that a data file has not yet been attached to the system. The box on the left side of the Where is MITI95.mdb? screen lists the available data files under the current directory (i.e., $\mathrm{C}: \mathrm{M}$ ITI). Clicking on mwirread.mdb (the entry will be highlighted) then selecting OK or pressing enter, for example, will attach the MWIR (MITI) Read Only Data to the system.

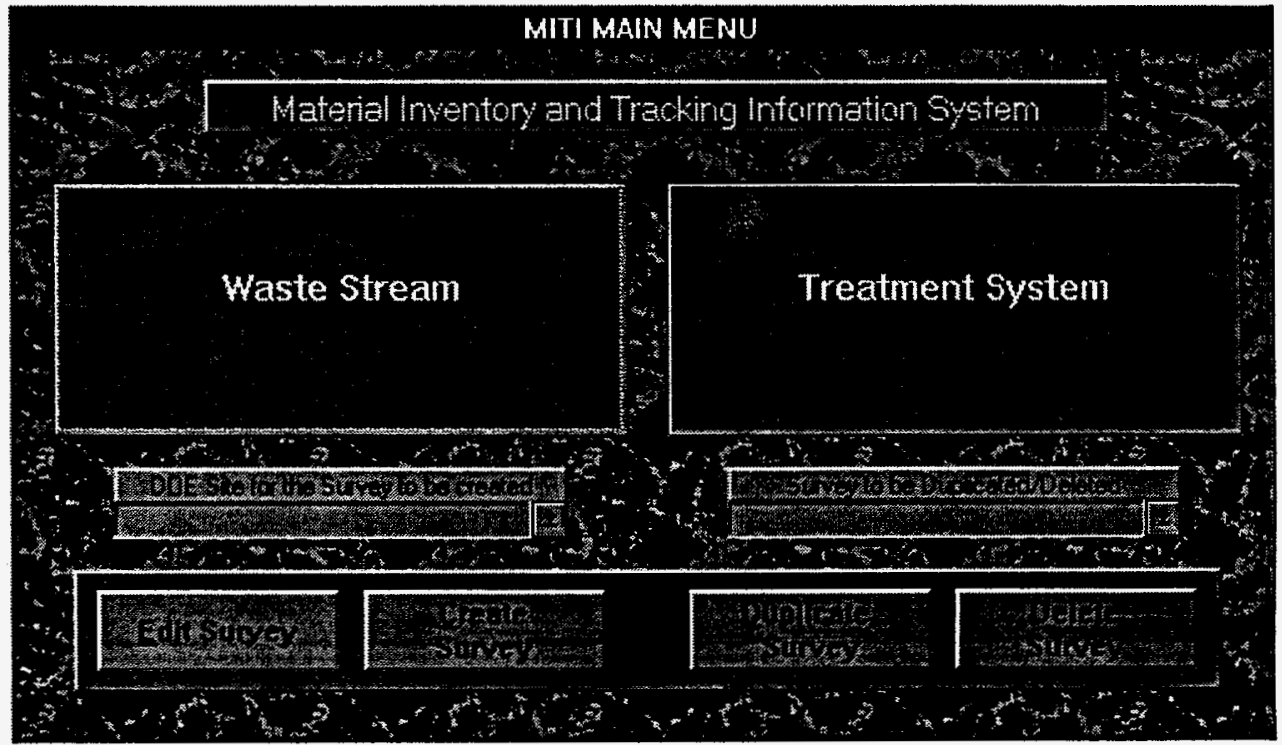

Figure 4-1. Main Menu screen. 
The Main Menu is the starting point for all operations conducted in MWIR-1995; selections available are:

- Two large buttons, Waste Stream and Treatment System

- Two field select boxes, DOE Site for the survey to be created and Survey to be Duplicated/Deleted

- $\quad$ Four smaller buttons, Edit Survey, Create Survey, Duplicate Survey, and Delete Survey.

NOTE: If you are attached to "read only" data, the Edit Survey button will read View Survey, and the Create Survey, Duplicate Survey, and Delete Survey buttons will be gray, indicating that they are inactive. Figure 4-2 shows the Main Menu as it appears when attached to "read only" data.

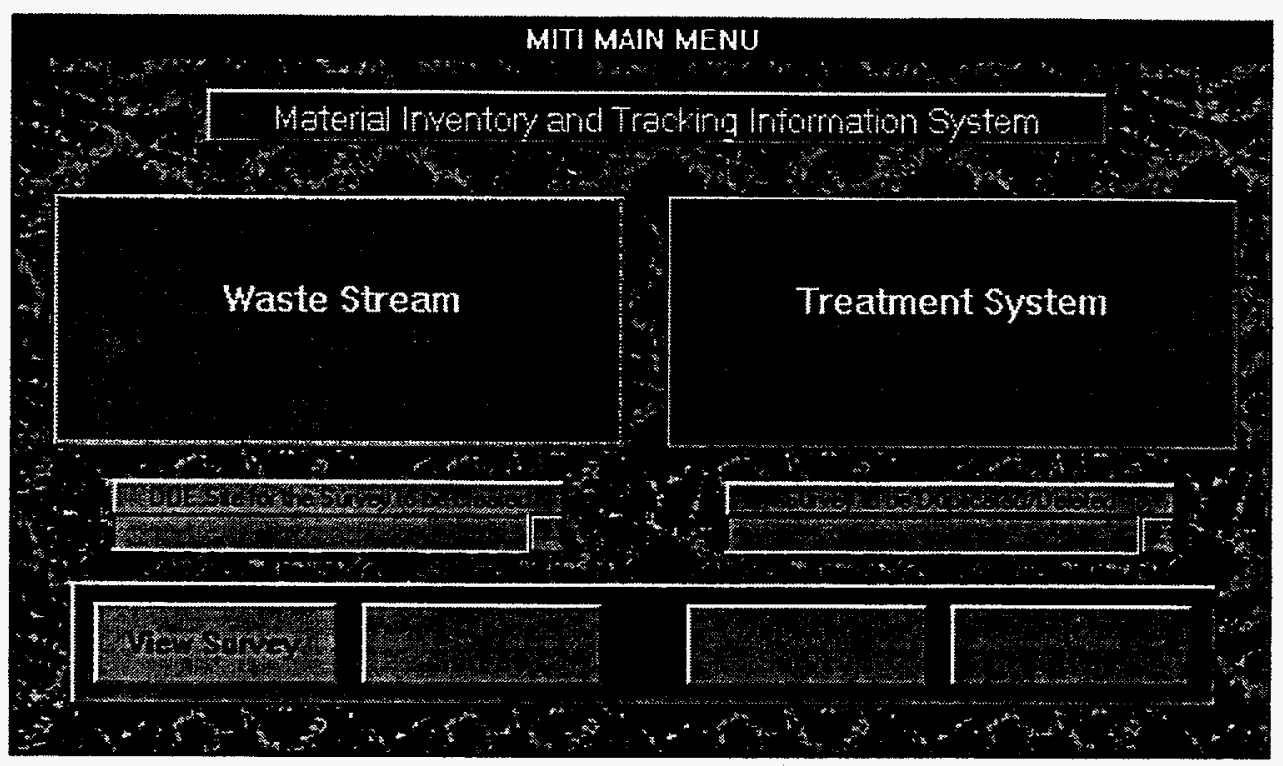

Figure 4-2. Main Menu screen (read only).

\subsection{Menu Bar}

The Menu Bar (Figure 4-3) includes selections for File, Edit, View, Records, Report, Window, and Help. The Menu Bar selections are discussed in detail in Appendix A. This is a good place to verify that the user is connected to the desired set of data; from the Menu Bar select Help; then select About MITI...; then select More...; the Data File: box will contain the path of the attached data; the default path is c:lmitilmwirread.mdb. The data set can be changed by going to Attach Data under the File option and selecting a new data set.

\section{File Edit View Records Report Window Help}

Figure 4-3. Menu Bar. 


\subsection{Tool Bar}

The Tool Bar (Figure 4-4) includes selections for Form View, Datasheet View, Print Survey, New, Save Record, Zoom In, Cut, Copy, Paste, Enter Query, Execute Query, Cancel Query, Undo, Undo Current Field/Record, Jump to Section, Query Builder, Spell Check, Previous Page, Next Page, Help, and Close Window. The Tool Bar selections are discussed in detail in Appendix B.

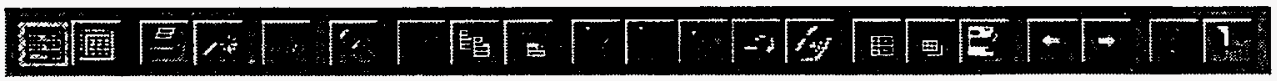

Figure 4-4. Tool Bar.

\subsection{Screens and Forms}

\subsubsection{Waste Stream Screens}

Each waste stream screen consists of two or more forms. The first form is the header. This information appears on every screen. When in Waste Stream the header background color is blue. Other colors on the screen depend on the colors selected by the user. The waste stream header contains fields for Site, Operations Office, State, Site Name, WS Name, Waste Type, Unique WS ID, and CPC Code.

\subsubsection{Treatment System Screens}

Each treatment system screen consists of two or more forms. The first form is the header. This information appears on every screen. When in Treatment System the header background color is green. Other colors on the screen depend on the colors selected by the user. The treatment system header contains fields for Site, Name, Operations Office, State, Facility, System, Status, Other, and Unique TS ID.

\subsubsection{Forms}

Each form in MWIR-1995 contains three parts: Title bar, Body, and Record Select Bar:

- The Title bar contains the name of the form

- The Body contains information associated with the form

- The Record Select Bar (Figure 4-5) allows a user to navigate to a desired record.

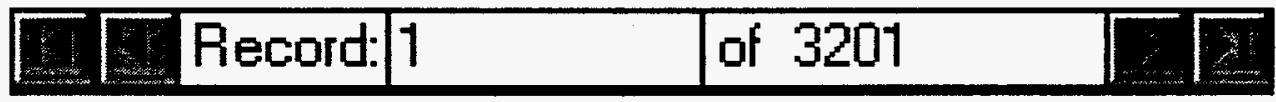

Figure 4-5. Record Select Bar. 
The Record Select Bar has the following structure:

- $\quad 14$ (Fast Reverse): Pressing the Fast Reverse button will take the user to record 1.

- 4 (Reverse): Pressing the Reverse button will take the user back one record from the current record.

- Record: Text indicating that the user is at the Record Select Bar.

- 1: Indicator that shows the current record. This can be used to rapidly move to a desired record. The record number can be highlighted and a new record number entered by the user. For example, if the user knows that record 1563 is the desired record, "1" can be highlighted and replaced with "1563". When the user presses enter, MWIR-1995 will navigate to the new record.

- of 3201: Indicator that shows the total records available. This can be used as the equivalent to a count query. In this case it represents the total number of waste streams in the MWIR-1995 database. If a form query is performed, this number will represent the number of records that satisfy the selection criteria.

- (Forward): Pressing the Forward button will take the user to the next record.

- (Fast Forward): Pressing the Fast Forward button will take the user to the last record. 


\section{VIEW DATA}

\subsection{View Survey}

When the Main Menu contains a View Survey button (instead of an Edit Survey button), "read only" data is attached. In this situation, the user is limited to viewing and querying data. The edit and update features of MWIR-1995 are disabled. This section provides an introduction to how to get to information of interest and various ways of viewing that information.

\subsubsection{Progressing Through Screens}

Advancing from the Main Menu to a desired screen can be accomplished in two ways: 1) stepby-step progression, or jumping directly to the desired form.

1. Step-by-step: This process is useful to cycle through each screen of a survey, to perform data entry, or to learn the data structure of MWIR-1995. Using it to view data can be time consuming.

- From the Main Menu click the button for the desired survey type. The choices are Waste Stream or Treatment System.

- Click the View Survey/Edit Survey button to advance to the first screen of the selected survey type.

- To get to the next screen, click the Next Page (blue right arrow) button on the toolbar.

- To get to subsequent screens, continue clicking the Next Page button, until the desired screen is displayed.

- To get to a previous screen, click the Previous Page button, until the desired screen is displayed.

2. Jump to Section: This process is useful when a specific form is desired. It presumes that the user has knowledge of what is contained in each form. In most cases the form title is sufficient description.

- From the Main Menu (or any other screen) click the Jump to Section button on the toolbar.

- This will display the System Forms dialog box (Figure 5-1).

- Double clicking on the title of the desired form will move the user to the screen that contains that form. Each record in the System Forms dialog box contains a general section number, a two letter code indicating that the record is associated with a waste stream (WS) or a treatment system (TS) survey, the title of the form, and in most 
cases the specific sections that are part of that form (e.g., 9.0 TS Waste Packaging Acceptance (9.2-9.4)).

- Repeat this process to move to other forms of interest.

\section{System Forms}

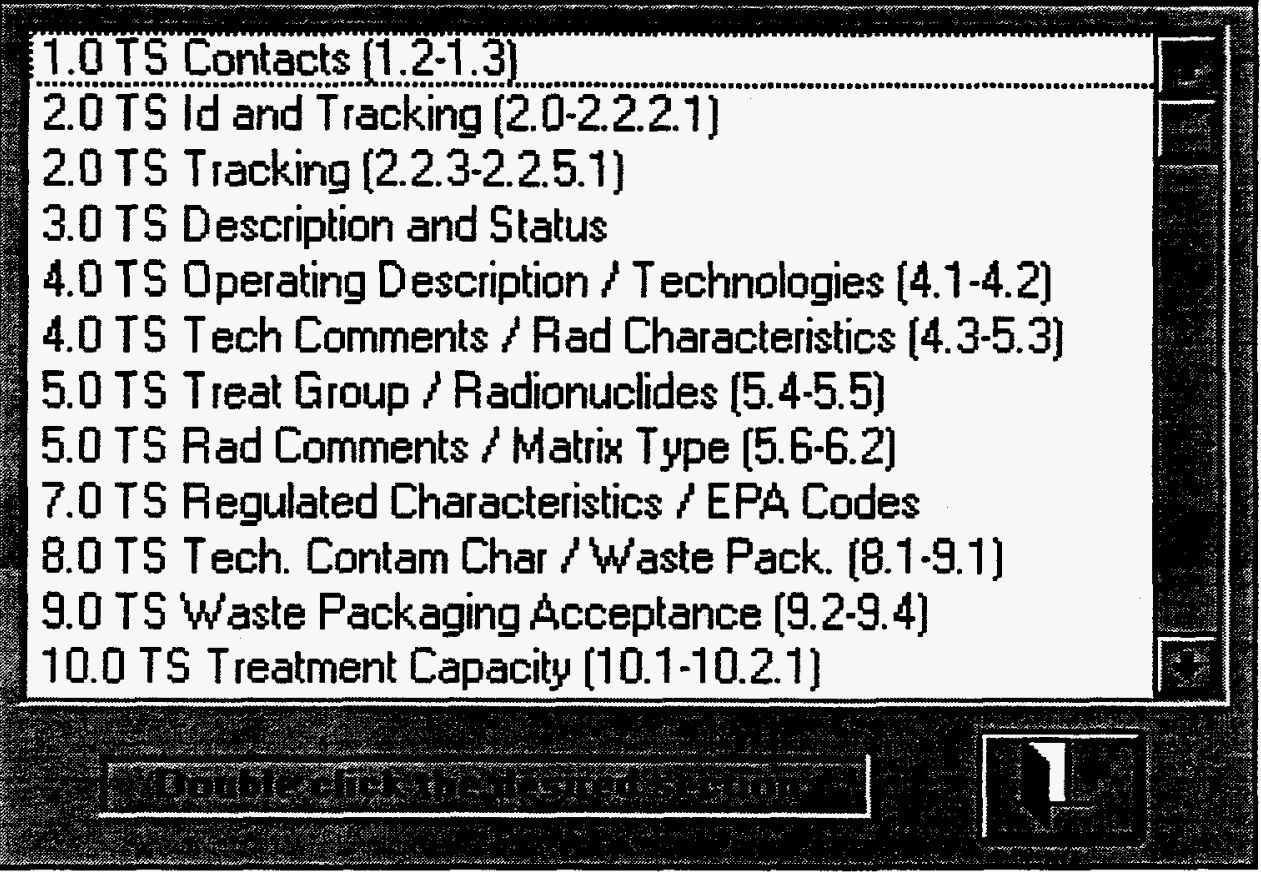

Figure 5-1. System Forms dialog box.

\subsubsection{Form Selection}

The previous section discussed how to get to various screens in MWIR-1995. This section provides information on how to select the form of interest and how to determine which form has been selected. When a form is selected it is called the active form; Only one form can be active. The active form has its title bar highlighted.

A form can be selected by clicking anywhere inside the form of interest. By default, the Waste Stream Information and Treatment System Information forms, or headers, are the active forms on each screen.

Once inside an active form, the user has several options available

- Form View: Form view is the default for MWIR-1995. The information is presented in a survey format so that the user can see the context of the data (survey question numbers and actual questions) that appears. Form queries are executed from the form view. See section 6.1, Form Query, for additional details. 
- Datasheet View: Displays the contents of the active form in a datasheet (spreadsheet) format (the field names of the data become the column titles of the datasheet). This can be an easier method of looking at the results of a form query.

- Form Query: Form Query is discussed in detail in Section 6 of this user guide.

\subsubsection{Maneuvering Inside Forms}

From the Main Menu progress to the screen that contains the desired information (see 5.1.1, Progressing Through Screens). For the purposes of the following examples, it is assumed that the user in on the first screen of Waste Stream surveys.

The default configuration for a screen has the Information form (Waste Stream Information or Treatment System Information) active and one or more inactive forms for related data.

The Record Select Bar for the Waste Stream Information form will indicate that the user is at record 1 of XXXX where XXXX is the number of waste stream records currently attached to MWIR1995 (If the screen is the results of a query, XXXX represents the number of records that meet the query criteria). Refer to Appendix A, part 7, Help, for a discussion on how to determine what dataset is currently attached to MWIR-1995.

From the information screens the user can enter and execute queries. Refer to section 6.1, Form Query, for additional information.

To move to the next record (the next waste stream):

- The user can press the forward button on the Record Select Bar (Figure 4-5). Note: pressing the next page button on the Tool Bar will take the user to the next screen of the same waste stream survey.

- The user can highlight "1" on the Record Select Bar and enter "2" (or any other number that represents the waste stream survey desired). When enter is pressed, MWIR-1995 will progress to waste stream record 2 .

This process is independent of the screens or forms. The only requirement is that the destination record must exist. If the user enters a record number that is greater than the total number of records attached, a message will appear, "Can't go to specified record". 


\section{QUERIES}

MWIR-1995 contains two powerful, yet easy to use tools for querying data. The Form Query option allows on-screen queries displayed in a form view mode. The Query Builder allows the user to define criteria accessing data from multiple tables; the Query Output can then be viewed, printed, or exported to Microsoft Access, Microsoft Excel, or .txt formats.

\subsection{Form Query}

Form query allows a user to select on-screen queries that will limit the records displayed to criteria defined by the user. This method of querying is easy to use and is quite effective in answering questions that require only one or two items of data. Examples of questions that are ideal for this type of query include: "How many waste streams are subject to RCRA regulations?" "How many waste streams are HLW?" "How many streams are currently stored?" "How many treatment facilities are mobile."

\subsubsection{How to Use Form Query}

On-screen form queries can be executed for either waste stream or treatment system data.

To execute a form query the user should select the screen that contains the information of interest. A form query can be executed from any form in the survey. Often there are multiple forms on one screen. When performing a form query the user is limited to the fields displayed in the active form (title bar is highlighted on the active form).

Move the cursor to the Tool Bar and select the Enter Query icon (funnel with a pencil). This will blank all the fields on the selected form.

Select the field of interest and identify the characteristic of interest.

Move the cursor to the Tool Bar and select the Execute Query icon (funnel with lines). This will bring up the information contained on the selected screen for all appropriate records. To view the queried information for the records that meet the query criteria, go to the Record Select Bar associated with the form that contains the characteristic of interest and select the record of interest.

If you select Enter Query and then change your mind, you can select the funnel with an X, labeled Cancel Query, and you will be returned to your original screen.

If you want to return MWIR-1995 to how it looks when first entered, select the Waste Stream Information form (i.e., header) or the Treatment System Information form (i.e., header) and select the Enter Query icon. This will blank all the fields on the selected form. Select the Execute Query icon. This will return all the information that applies to the selected form. This is called a blind query. 


\subsubsection{Form Query Examples}

Example 1: A user interested in waste streams where the response to the presence of PCBs is "No" would perform the following steps:

1. From the Tool Bar select the Jump to Section icon.

2. From the System Forms dialog box select 3.4 WS PCBs/Asbestos (3.4.3.1 - 3.4.8).

3. This takes the user to the screen that contains information about PCBs; select the form that contains PCB information.

4. From the Tool Bar select Enter Query.

5. Go to the question Does this waste stream contain PCBs? and from the list of values select No.

6. From the Tool Bar select Execute Query.

7. This will return all waste streams where the response to this question was "No."

8. The Record Select Bar for the queried form will list the number of records that meet the query criteria and will allow viewing of that record for those waste streams.

NOTE: When the user moves to another screen, MWIR-1995 assumes that you are interested in only the waste stream that you were viewing when you moved to that new screen.

Example 2: A user is interested in HLW streams. Since this information is part of the Waste Stream Information form (the header), it can be queried from any screen. The user would perform the following steps:

1. Select the Waste Stream Information form.

2. From the Tool Bar select Enter Query.

3. Go to the Waste Type field and from the list of values select HLW.

4. From the Tool Bar select Execute Query.

5. This will return all waste streams where the waste type is $\mathrm{HLW}$.

6. The Record Select Bar for the queried form will list the number of records that meet the query criteria and will allow normal viewing of those waste streams.

Example 3: A user that is interested in treatment systems that are mobile would perform the following steps: 
1. From the Tool Bar select the Jump to Section icon.

2. From the System Forms dialog box select 2.0 TS Id and Tracking (2.0 - 2.2.2.1).

3. This takes the user to the screen that contains information about the mobility of treatment systems; select the form that contains Mobile information.

4. From the Tool Bar select Enter Query.

5. Go to the question, 2.1.7 Mobile, and select Yes from the list of values.

6. From the Tool Bar select Execute Query.

7. This will return all treatment systems where the response to this question was "Yes."

8. The Record Select Bar for the queried form will list the number of records that meet the query criteria and will allow viewing of that record for those treatment systems.

NOTE: When the user moves to another screen, MWIR-1995 assumes that you are interested in only the treatment system that you were viewing when you moved to that new screen.

Example 4: A user is interested in treatment systems that are currently operating. Since this information is part of the Treatment System Information form (the header), it can be queried from any screen. The user would perform the following steps:

1. Select the Treatment System Information form.

2. From the Tool Bar select Enter Query.

3. Go to the Status field and from the list of values select Operating.

4. From the Tool Bar select Execute Query.

5. This will return all treatment systems where the status is operating.

6. The Record Select Bar for the queried form will list the number of records that meet the query criteria and will allow normal viewing of those treatment systems.

Example 5: A user that is interested in treatment systems that can accept TRU waste would perform the following steps:

1. From the Tool Bar select the Jump to Section icon.

2. From the System Forms dialog box select 4.0 TS Tech Comments/Rad Characteristics (4.3-5.3). 
3. This takes the user to the screen that contains information about treatment system technologies and radioactive characteristics of acceptable waste; select the form that contains treatment system acceptable waste type.

4. From the Tool Bar select Enter Query.

5. Go to the Waste Type field and from the list of values select TRU.

6. From the Tool Bar select Execute Query.

7. This will return all treatment systems where the acceptable waste type is TRU.

8. The Record Select Bar for the queried form will list the number of records that meet the query criteria and will allow normal viewing of those treatment systems.

NOTE: When the user moves to another screen, MWIR-1995 assumes that you are interested in only the treatment system that you were viewing when you moved to that new screen.

One of the drawbacks associated with form query is the user is limited to the fields displayed in the active form.

\subsection{Query Builder}

Query Builder allows the user to develop queries independent of on-screen forms that enable the user to answer more detailed questions. The Query Builder allows the user to select fields from single or multiple tables, to define criteria, and to order the output. The output from the query is displayed in a spreadsheet view mode; however, the output can be printed or the data can be exported to Microsoft Access, Microsoft Excel, or .txt format. The query cannot be rerun.

Examples of queries that could be answered with a Query Builder query include, "What is the inventory of waste that contains a D009 code?" "How many remote-handled MLLW streams contain PCBs?" "How many operating wastewater units are there?"

\subsubsection{How to use Query Builder}

1. From the toolbar select Query Builder (the button with xyz).

2. From the Query Builder select table dialog box (Figure 6-1) then select the table(s) of interest.

3. Click the next page button on the Query Builder select tables(s) dialog box.

From the Query Builder select fields dialog box (Figure 6-2) select the field(s) of interest: Once one field has been selected other options become available; these options are Make Query, New Query, Criteria/Joins, Previous Page, SQL, and Close Form: 
Query Builder

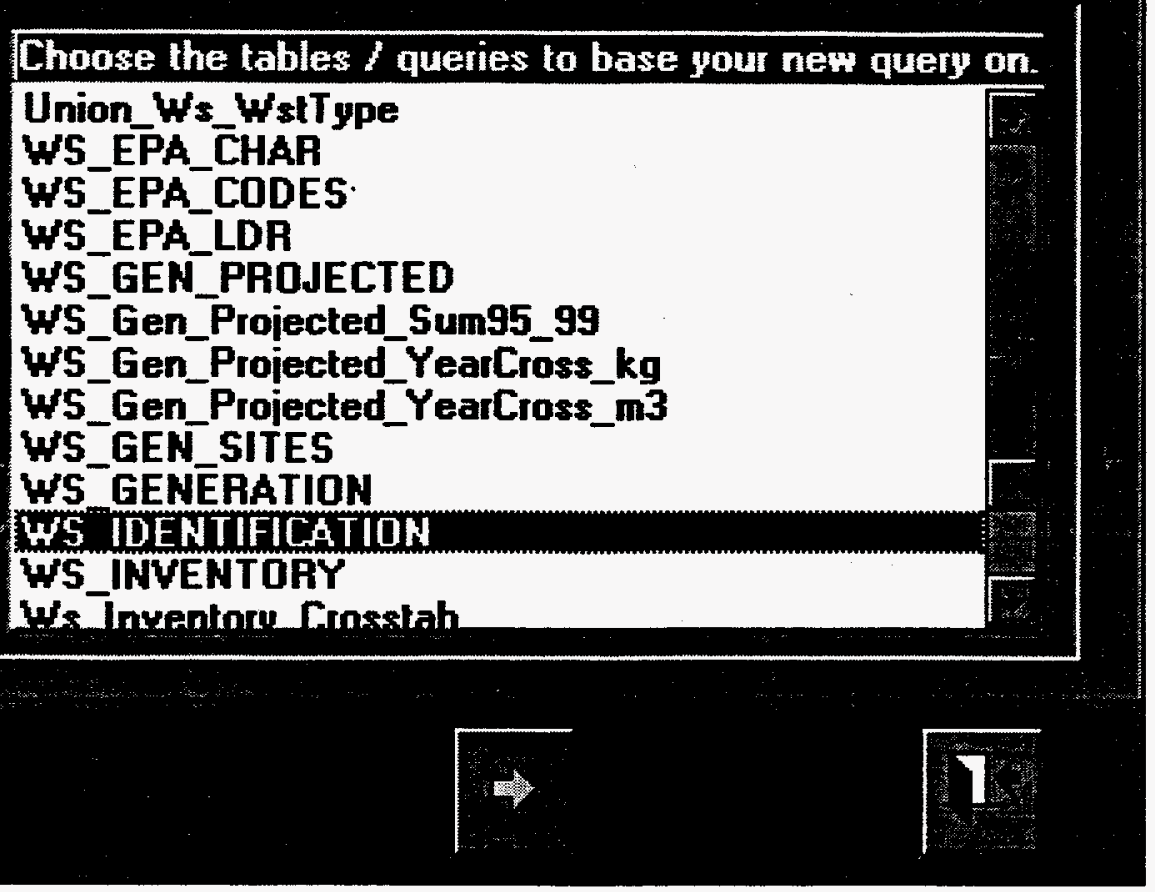

Figure 6-1. Query Builder select tables dialog box.

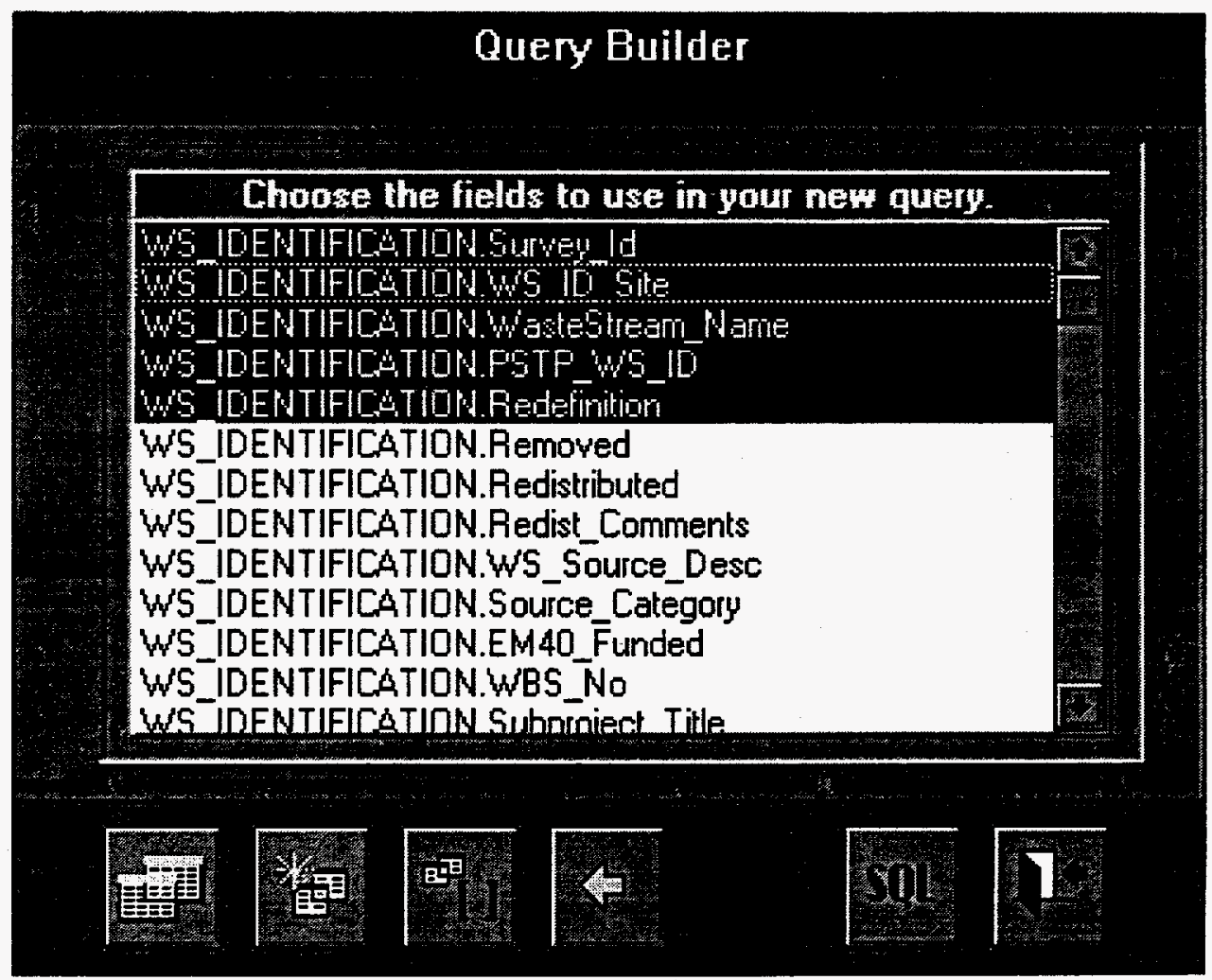

Figure 6-2. Query Builder select fields dialog box. 
- $\quad$ Make Query: Executes the query

- New Query: Cancels the current query and returns the user to the select table(s) dialog box

- Criteria/Joins: Allows the selection of one or more join criteria and sort order criteria. These criteria are inserted into an SQL text box where they can be further edited if necessary; the close form button commits the criteria to the SQL.

- Previous Page: Returns to the select table(s) dialog box

- $\quad$ Close Form: Exits the Query Builder (do not save any layout changes or queries; saving layout changes uses additional memory and saved queries cannot be run using MWIR-1995)

\subsubsection{Query Builder Examples}

Example 1: A user who wants to determine how many treatment units will treat waste with matrix codes that begin with " $\mathrm{X}$ " would perform the following steps:

1. Select Query Builder.

2. Select table TRT_MPC.

3. Press the next page button (blue right arrow).

4. Select the fields TRT_MPC.Survey_Id and TRT_MPC.MPC_Code.

5. Select the Criteria/Joins button (third from left).

6. In the box entitled Joins/Criteria select field name of [TRT_MPC].[MPC_Code] and operator of Like and criteria of "X*"; follow the selection of the criteria by pressing the insert button; this will move the selection criteria into the text box below.

7. Press the close form button to exit the screen.

8. Execute the query by pressing the make query button (first button on the left).

9. A dialog box will appear with a request to enter the name of your query. Enter any name that is meaningful to you. Select $\mathbf{O K}$ or press enter.

10. Review the data; at this point the user can exercise many options including changing the font and size of the display or send the output to a file or the printer.

11. To exit this screen select close from the control menu box (The control menu box is the "dash" or short horizontal bar on the left end of the Select Query title bar). 
12. Exit the Query Builder by clicking the Close Form button on the lower left of the Query Builder screen.

13. The system asks Do you want to delete the query cannot be re-executed once you exit this screen). :; select yes (the query

Example 2: A user who wants to determine how many remote-handled TRU or MTRU streams do not contain PCBs would perform the following steps:

1. Select Query Builder.

2. Select table WS_RAD_CHAR and then select table WS_EPA_CHAR.

3. Press the Next Page button (blue right arrow).

4. Select the fields; for this query select:

WS_EPA_CHAR.Survey_Id, WS_EPA_CHAR.PCB, and WS_RAD_CHAR.RPC_Code.

5. Select the Criteria/Joins button (third button from left).

6. For this query there are multiple criteria: in the box entitled Joins/Criteria select field name of [WS_EPA_CHAR].[Survey_Id] and operator of $=$ and criteria of

[WS_RAD_CHAR].[Survey_Id]; press the insert button; select [WS_EPA_CHAR].[PCB] and operator of = and criteria of "No"; press the insert button; select

[WS_RAD_CHAR].[RPC_Code] and operator of = and criteria of "TR-RH"; follow the selection of the criteria by pressing the insert button; the text box should include code that looks like Where [WS_EPA_CHAR].[Survey_ID] $=$ [WS_RAD_CHAR].[Survey_ID] and [WS_EPA_CHAR].[PCB] $=$ "No" and [WS_RAD_CHAR].[RPC_Code] $=$ "TRRH".

7. Press the close form button to exit the screen.

8. Execute the query by pressing the Make Query button (first button on the left).

9. A dialog box will appear with a request to enter the name of your query. Enter any name that is meaningful to you. Select OK or press enter.

10. Review the data; at this point the user can exercise many options including changing the font and size of the display, or send the output to a file or the printer.

11. To exit this screen select close from the control menu box (The control menu box is the "dash" or short horizontal bar on the left end of the Select Query title bar).

12. Exit the Query Builder by clicking the Close Form button on the lower left of the Query Builder screen. 
13. The system asks Do you want to delete the query :; select yes (the query cannot be reexecuted once you exit this screen). 


\section{PRINTING SURVEYS AND STANDARDIZED REPORTS}

\subsection{Introduction-Printing in MWIR-1995}

Several options are available for printing surveys and standard reports. The system allows the user to print complete, condensed, or specific portions of one or several surveys. Standard reports can be developed according to specific parameters, viewed on screen to ensure that proper parameters are included, and printed when the report meets user needs. Before printing surveys or standardized reports, make sure the printer is properly set up.

\subsection{Setting Up The Printer}

A user can set up a printer from either the Main Menu or any screen within a waste stream or treatment system survey by performing the following:

1. Select File from the Menu Bar.

2. Select Print Setup from the pull-down menu.

3. In the Print Setup screen (shown in Figure 7-1), verify that the user's current printer is selected as the default printer; if the printer is not selected as the default printer, there are several options for selecting the printer; a user may select any/one of the following options:

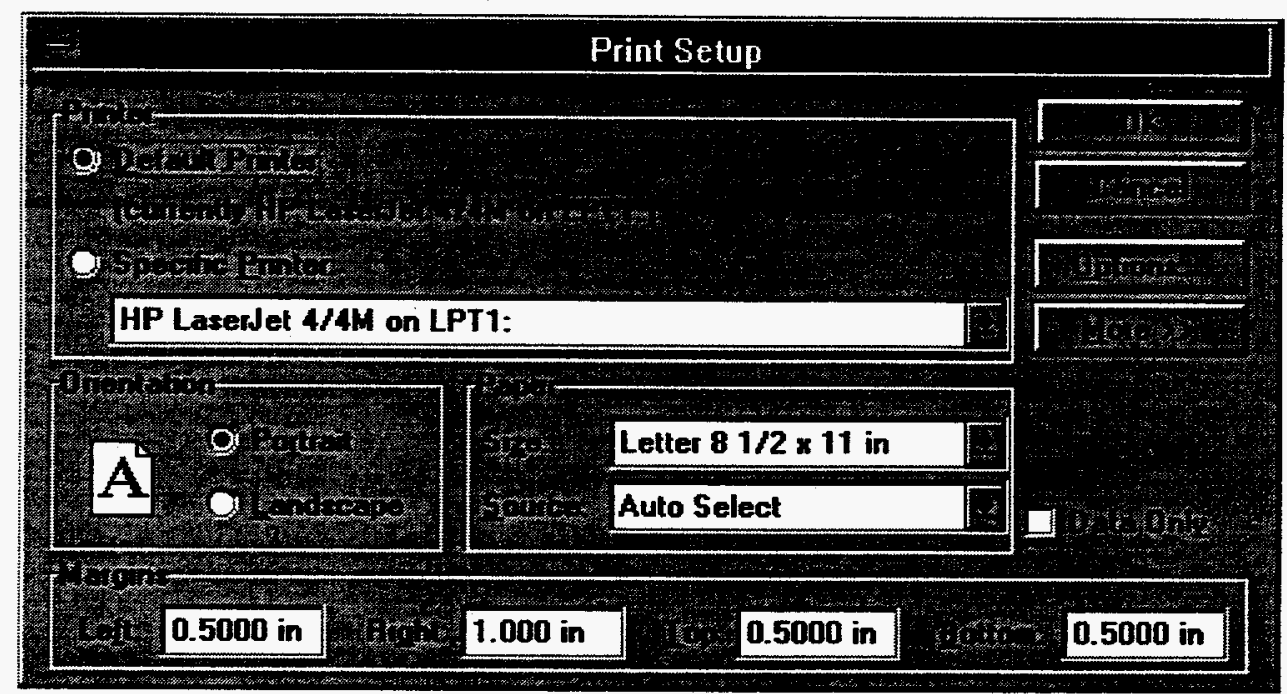

Figure 7-1. Print Setup screen.

- To permanently select a printer as the default printer, exit the system and set the printer default in Windows. After getting to the Windows screen, sequentially select the Main icon, the Control Panel icon, and the Printers icon. The default printer listed in the window should be the same printer shown in the MWIR-1995 printer setup window. To select a different printer, review the list provided in the Installed Printers list and highlight the desired printer. Select the Set as Default Printer button 
and the Close button. This series of steps should set the default printer in the MWIR1995 Print Setup screen. For additional assistance for these steps, refer to the Windows user guide.

- To temporarily select a printer as the default, do not exit the system. Select the Specify Printer button in the MWIR-1995 Print Setup screen. Scroll through the available printers and select the desired printer. The printer driver selected will remain active until the system is exited. If the user exits the system and re-enters the system, the default printer will be activated.

NOTE: If the desired printer is not listed in the Specify Printer list, install the driver in Windows. (See Step A above or refer to the Windows manual.)

By specifying the printer connected to the user's PC, the user should be able to complete all the printing options discussed in this chapter. The following notes discuss limitations and problems that may be faced while printing. The solutions recommended should resolve most problems; if a unique problem arises that is not addressed, contact Technical Support (see Section 9).

NOTE 1: Do not attempt printing surveys or reports from the File selection from the Menu Bar. The File selection provides a pull-down menu to set up the printer. Selecting Print from that pull-down menu will cause problems that may require substantial paper or toner and/or resetting of the users printer. For best results, use either the Printer icon form, the Tool Bar, or the Report selection from the Menu Bar to print surveys or reports.

NOTE 2: Sometimes surveys or reports print beyond established boundaries or margins or other format problems, the printer selection may have to be changed. The best solution is to select a HP LaserJet II as the default printer in either Windows or MWIR-1995 (as discussed above). If selecting the LaserJet II does not solve the problems, contact Technical Support (see Section 9).

\subsection{Printing a Waste Stream or Treatment Survey}

The printing options provided in MWIR-1995 allow a user to print a complete waste stream or treatment system survey, a condensed or short version of a waste stream or treatment system survey, or selected sections from a waste stream or treatment system survey. The printing options also allow printouts of several complete surveys, several short version surveys, or selected sections from several surveys.

Surveys can be printed from either the Main Menu, any screen in a Waste Stream Survey, or any screen in a Treatment System Survey. Surveys may be printed using the Printer icon on the Tool Bar, or the Report selection on the Menu Bar. To print from the Printer icon, select the icon and the Print Survey Options screen will appear on screen. To print from the Menu Bar, select Report followed by selecting Print Survey from the pull-down menu and the Print Survey Options screen will appear. The Print Survey Options screen shown in Figure 7-2 provides all the available options for printing waste stream and treatment system surveys. 


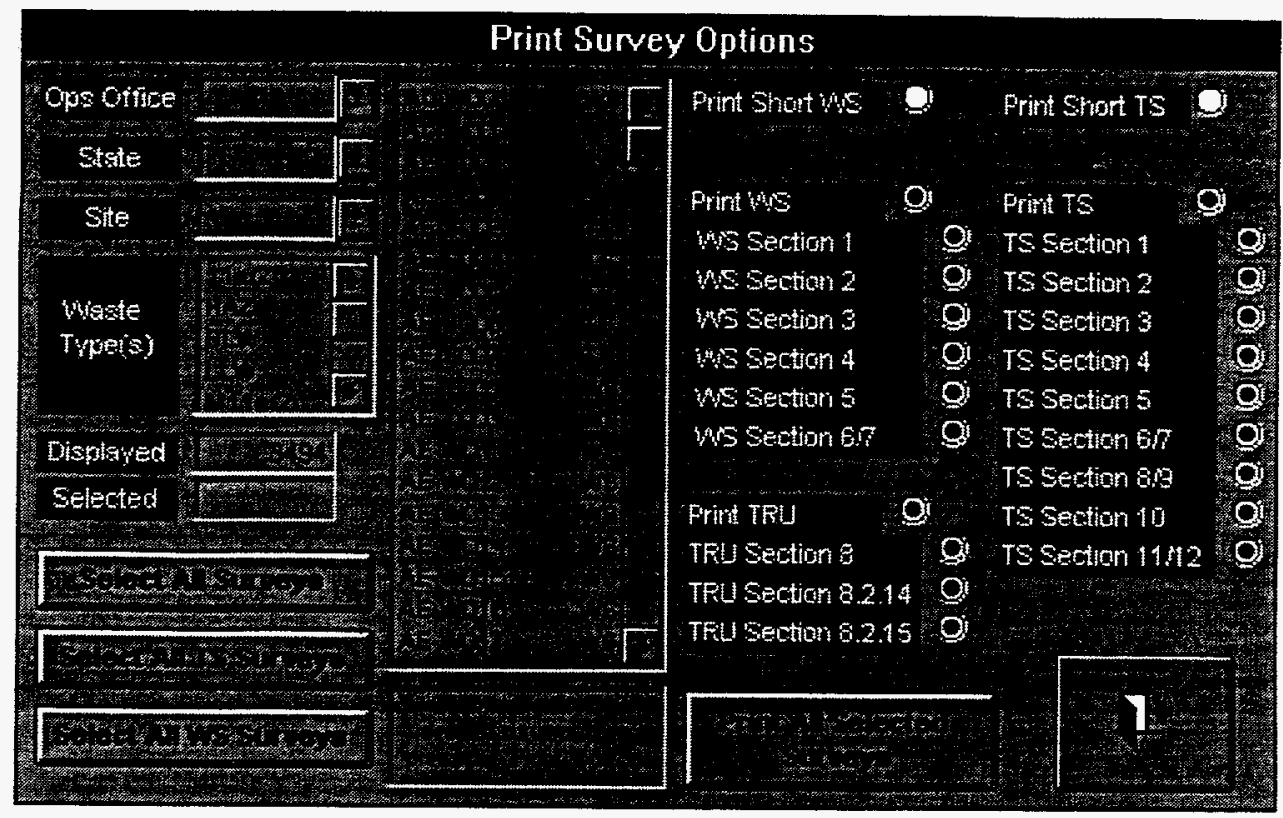

Figure 7-2. Print Survey Options screen.

\subsubsection{Printing a Complete Survey}

After entering the Print Surveys Options screen, one complete waste stream or treatment system survey can be printed by performing the following steps:

1. Highlight the appropriate survey from the list of waste stream or treatment system identification numbers found in the middle list box of the window.

2. Select the Print WS radio button for printing a complete waste stream survey, the Print TS radio button for printing a complete treatment system survey, or both if at least one of each type of survey is highlighted. The radio buttons are selected when a small black circle occupies the majority of the white circle background. The system default is having both Print WS and Print TS radio buttons selected, so that should be the setting when the window appears. Selecting Print WS also selects WS Sections 1-7, which is normal. Selecting Print TS also selects TS Sections 1-12, which is also normal.

3. Select the Print All Selected Surveys button to print the survey.

4. Select the Close Window (the closing door with an arrow) button to exit the Print Survey Options screen.

\subsubsection{Printing a Short Version Survey}

The short version survey provides a condensed waste stream or treatment system report. The short version survey is comprised of several standard key fields. The waste stream short version survey includes site information, the name and telephone number of the primary technical contact at 
the site for the waste stream, waste stream description, waste type, matrix code, EPA and state hazardous waste codes, current inventory, generation projections, and storage information. The treatment system short version survey includes site information, the name and telephone number of the primary technical contact at the site for the treatment system, system description, system status, general treatment technologies, general waste acceptance criteria, scale of the system, and annual throughput values.

After entering the Print Survey Options screen, the user can print a short version of a waste stream or treatment system survey by performing the following steps:

1. Highlight the appropriate survey from the list of waste stream or treatment system identification numbers found in the middle list box of the window.

2. Select the Print Short WS radio button for printing a short version of a waste stream survey, the Print Short TS radio button for printing a short version of a treatment system survey, or both if at least one of each type of survey is highlighted. Selecting the Print Short WS radio button will unselect the Print WS, and WS Sections 1-7 radio buttons. Selecting the Print Short TS radio button will unselect the Print TS, and TS Sections 1-12 radio buttons.

3. Select the Print All Selected Surveys button to print the short version of the survey.

4. Select the Close Window (the closing door with an arrow) button to exit the Print Survey Options screen.

\subsubsection{Printing Selected Portions of a Survey}

After entering the Print Survey Options screen, any section of a waste stream or treatment system survey can be printed by performing the following steps:

1. Highlight the appropriate survey from the list of waste stream or treatment system identification numbers found in the middle list box of the window.

2. Select any WS Section radio button for printing a portion of a waste stream survey, or any TS Section radio button buttons for printing a portion of a treatment system survey. Several radio buttons can be selected to print more than one section of a survey. Combinations of both WS Section and TS Section radio buttons can be selected if at least one of each type of survey is highlighted.

3. Select the Print All Selected Surveys button to print the portion of the survey.

4. Select the Close Window (the closing door with an arrow) button to exit the Print Survey Options screen. 


\subsubsection{Printing Several Surveys}

Several options are available to print one or more surveys. The system can be used to view only the surveys associated with certain DOE Operations Offices, host states, DOE sites, radiological waste types, or any combination of all four parameters. While viewing a subset of surveys, a user may select one, several, or all of the surveys presented for printing. Double check the selection prior to sending the print job to avoid printing unwanted pages of survey information.

7.3.4.1 Selecting Several Surveys. The middle list box of the Print Survey Options screen provides the list of waste stream and treatment system surveys currently in MWIR-1995. Not all system users received the same listing of surveys, so a user should not be surprised if their list is different from another user. To select more than one survey, first select one survey by pointing the cursor and clicking the mouse button. The survey should become shaded or highlighted. Next, press the CTRL key, point the cursor at the second survey, and click the mouse button while keeping the CTRL key pressed. Repeat the process until all surveys are selected. Remember to keep the CTRL key depressed when selecting additional surveys. If CTRL key is not depressed when additional surveys are selected, all previously selected surveys will be unselected and the survey selection process will have to be repeated.

In addition to selecting individual surveys, a user may select a specific block of surveys, all the waste stream surveys, all the treatment system surveys, or all surveys. To select a block of surveys (a list of contiguous surveys), select the uppermost or first survey in the list. Next, press the SHIFT key and select the last survey in the list. Every survey in the block should be shaded or highlighted. To select another block of surveys, press the CTRL key while selecting the first survey of the second block, and press the CTRL key and the SHIFT simultaneously (CTRL+SHIFT) while selecting the final survey in the list. Multiple blocks can be selected in this manner. The user can also press the CTRL key to select a survey outside the block or to deselect a survey within the block. To select all waste stream surveys in the list, select the Select All WS Surveys button. To select all treatment system surveys in the list, select the Select All TS Surveys button. To select all surveys in the list, select the Select All Surveys button. To deselect a subset block of surveys, press the CTRL key to deselect the first survey and CTRL+SHIFT to deselect the last survey of the block. The result is an unselected block, which will be unshaded inside the block of shaded surveys.

7.3.4.2 Viewing a Specific List of Surveys. The upper left hand corner of the Print Survey Options screen includes list boxes for establishing criteria for viewing waste streams. The list boxes directly adjacent to the labels Ops Office, State, Site, and Waste Type(s) allow the user to view only the surveys associated with particular DOE Operations Offices, states hosting DOE facilities, DOE sites, and/or waste types. By selecting the list box arrow adjacent to the list box, the appropriate list of Operations Offices, hosts states, sites, and waste types will appear for the waste stream and treatment system surveys currently in the users specific version of MWIR-1995. As selections are made from these lists, the list of surveys in the middle list box will shorten to reflect the selection. The list is hierarchial in the order Ops Office, State, Site, and waste type. This means that selecting a particular Ops Office will restrict the user to selecting host states, DOE sites, and waste types associated with that Ops Office. By selecting a particular Ops Office and a particular host state, the user will be restricted to selecting only DOE sites that meet both criteria. When a new Ops Office selection is made, all State, Site, and Waste Type selections will be reset. After selecting a particular 
Ops Office, the user can retrieve the complete list of surveys for all Ops Offices by exiting and reentering the Print Survey Options screen.

Please note that the only waste stream surveys in MWIR-1995 should be HLW, M1 le(2), MLLW, MTRU, Null, and TRU. The waste type list box in the Print Survey Options screen also includes $11 \mathrm{e}(2), \mathrm{HAZ}$, and LLW. The additional waste types are included since treatment systems can receive a wide variety of waste. The only surveys in MWIR-1995 associated with waste types 11 (2), HAZ, and LLW should be treatment system surveys.

\subsection{Developing and Printing Standardized Reports}

MWIR-1995 includes three report generators for developing custom reports in a standard format. The report generators are located under the Report selection in the Menu Bar. The three report generators are the Waste Type Report Options, Waste Stream Report Options, and the Treatment System Report Options. Each report generator provides several options for formatting and printing the information in MWIR-1995.

All three of the report generators include three fields that may not be familiar to most system users but are very useful in customizing reports. The fields are the Radiological Parameter Category (RPC), the Matrix Parameter Category (MPC), and the Contaminant Parameter Category (CPC). Each of the fields are coded to represent a series of waste stream characterization information. The RPC code includes the waste type, handling requirements, transuranic alpha contamination concentration level, and non-transuranic alpha contamination concentration level of the waste stream. The MPC code includes the physical and chemical matrix of the waste stream. The CPC code includes the regulatory classification and indicates all combinations of the organic contamination, metals contamination, and characteristics of ignitability, corrosivity, and reactivity of the waste stream. All three fields are fully defined and explained in the DOE Waste Treatability Group Guidance (DOE/LLW-217 Rev. 0). A copy of the guidance can be obtained by contacting Technical Support (see Section 9).

\subsubsection{Waste Type Report Options}

The waste type report generator is intended to provide a very general report for waste stream information. The Waste Type Report Options screen is accessed by selecting Waste Stream, then Waste Type Report from the pull-down menu from the Report selection on the Menu Bar. The Waste Type Report Options screen is shown in Figure 7-3.

The waste type report provides a summary of current inventory and generation projection values for all surveys for a particular DOE Operations Office, a state hosting DOE facilities, or a DOE site. After entering the Waste Type Report Options screen, print the waste type report by performing the following steps:

1. Highlight the appropriate Ops Office, State, or Site from the list boxes on the left hand side of the window. 


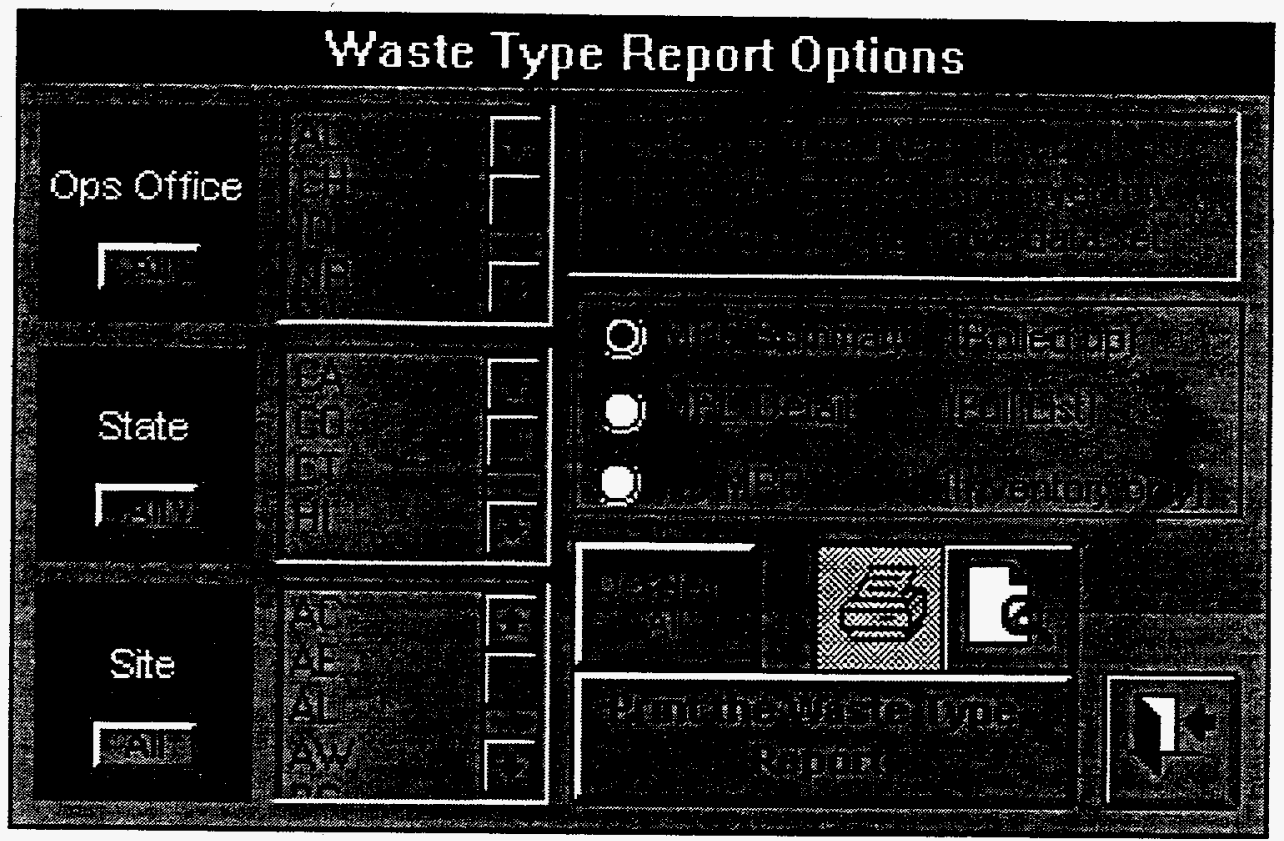

Figure 7-3. Waste Type Report Options screen.

2. Select either the MPC Summary (Rolled up), MPC detail (Full list), or No MPC (Inventory Only) radio button to determine the type of report the user wants printed.

3. Select the Print to the Printer (the printer icon) or the Print to Screen (the icon with a sheet of paper and a magnifying glass) button. It is recommended to print to screen and review the report before sending the report to the printer.

4. Select the Print the Waste Type Report button.

5. Select the Close Window (the icon with a closing door and an arrow) button to exit the Waste Type Report Options screen.

The Ops Office, State, and Site list boxes are hierarchial. This means that selecting a particular Ops Office will restrict the user to only select host states and DOE sites associated with that Ops Office. By selecting a particular Ops Office and a particular host state, the user will only be allowed to select DOE sites that meet both criteria. To select all DOE Ops Offices, States, or Sites, select the All button for any of the list boxes. A user may select one Ops Office, one State, and then use the All button to select all Sites under that Operations office and host state. To deselect all Ops Office, State, and Site selections, select the Deselect All button in the middle of the window.

The MPC Summary, MPC Detail, and No MPC radio buttons provide different options for levels of report detail. The MPC Summary report rolls up the inventory and projection values by radiological waste type for each site according to thirty four general matrix categories found in the DOE Treatability Group Guidance (DOE/LLW-217. Rev. 0.). The thirty four categories define the level of detail presented in the annual DOE Baseline Environmental Management Report. The MPC Detail report provides the inventory and projection values by radiological waste type for each site 
according to all one hundred fifty two matrix categories found in the DOE Treatability Group Guidance (DOE/LLW-217, Rev. 0.). The No MPC report provides inventory and projection values by radiological waste type for each site.

The Print to Screen (the icon with a sheet of paper and a magnifying glass) button allows the user to review the report before sending it to the printer. Completing this step before printing is highly recommended so that the user receives only the requested information. After selecting the button, an on-screen version of the report will appear. The Tool Bar allows the user to zoom, set up the printer, print to printer, print to file, or return to the Waste Type Report Options screen. The Zoom icon appears as a magnifying glass and allows the user to zoom from a close up of the report to a full page and vice versa. The Printer Setup icon appears as a sheet of paper with margin lines and allows the user to change printing options. The Print to File icon appears as an arrow pointing to a spreadsheet and allows the user to export the report as a Microsoft Excel 3.0 file (*.xls), a Rich Text Format file $\left({ }^{*} . \mathrm{rtf}\right)$, or an MS-DOS Text file $\left({ }^{*} . \mathrm{txt}\right)$. The file will be located in the MWIR-1995 directory, unless otherwise specified. The Print to Printer icon appears as a printer and allows the user to print on another printer. The Close Window icon appears as a closing door with an arrow and allows the user to return to the Waste Type Report Options screen after reviewing the report. It is recommended that users who have not used this report generator print all reports to the screen, zoom out to see the entire report, and note the number of pages that will be printed. To reach the last page of the report, use the Page Down key on the computer keyboard or use the Record Select Bar in the lower left hand corner of the screen, then select the fast forward button, which looks like a greater than sign followed by a vertical line $(-1)$. Review the report before printing it. If the report is not what was anticipated, close the window and review or modify the report selections in the Waste Type Report Options screen, and try again. After becoming familiar with the report generator, the user may want to begin printing directly to the printer.

\subsubsection{Waste Stream Report Options}

The waste stream report generator is intended to provide a specific report for one or more individual waste streams. To enter the Waste Stream Report Options screen, select Waste Stream, then Waste Stream Report from the pull-down menu from the Report selection on the Menu Bar. The Waste Stream Report Options screen is shown in Figure 7-4.

The waste stream report provides the waste stream identification number, waste stream name, RPC code, MPC code, CPC code, current inventory in mass and volume, and a five-year generation projection in mass and volume for each survey associated with a particular DOE Operations Office, state hosting DOE facilities, or DOE site. After entering the Waste Stream Report Options screen, print the waste stream report by performing the following steps:

1. Highlight the appropriate Ops Office, State, Site, or Waste Type from the list boxes on the left hand side of the window.

NOTE: If a Waste Type is selected then the user cannot select an RPC Mask, an MPC Mask, or a CPC Mask. 
2. Select either the RPC Mask, MPC Mask, or CPC Mask, if desired, from the list boxes in the upper right hand portion of the window. These list boxes allow the user to select general or very specific waste stream categories.

NOTE: If a Waste Type was selected in step 1., an RPC Mask, an MPC Mask, or a CPC Mask cannot be selected in this step.

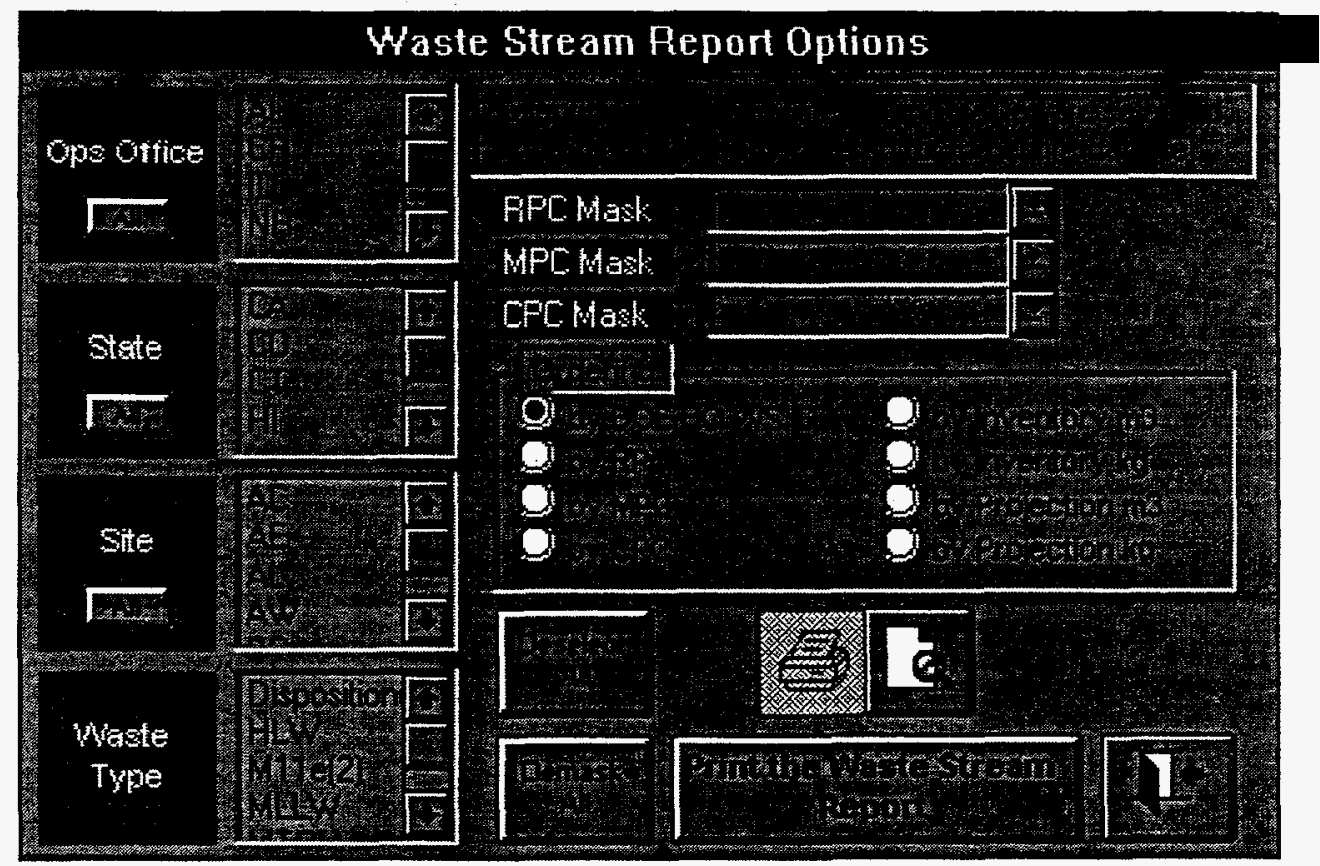

Figure 7-4. Waste Stream Report Options screen.

3. Select one radio button to determine the order of the waste streams. They can be sorted by waste stream identification number, RPC, MPC, CPC, inventory value, or projection value.

4. Select the Print to the Printer (the printer icon) or the Print to Screen (the icon with a sheet of paper and a magnifying glass) button. It is recommended that a user print to screen and review the report before sending the report to the printer.

5. Select the Print the Waste Stream Report button.

6. Select the Close Window (the icon with a closing door and an arrow) button to exit the Waste Stream Report Options screen.

The Ops Office, State, Site, and Waste Type are hierarchial in order. This means that selecting a particular Ops Office will restrict the user to only select host states, and DOE sites associated with that Ops Office. By selecting a particular Ops Office and a particular host state, the user will be restricted to DOE sites that meet both criteria. To select all DOE Ops Offices, States, or Sites, select the All button for any of the list boxes. To select one Ops Office or one State, use the All button to 
select all Sites under that Operations office and host state. To deselect all Ops Office, State, Site, and Waste Type selections, select the Deselect All button in the middle of the window.

The RPC Mask, MPC Mask, and CPC Mask list boxes allow the user to be very selective regarding which waste streams to list in a report. The RPC codes, MPC codes, and CPC codes needed for masking can be found in the DOE Treatability Group Guidance (DOE/LLW-217, Rev. 0). Entering a RPC code allows a user to specify waste streams with certain radiological parameters, including waste type, waste handling, transuranic alpha contamination concentration level, and nontransuranic alpha contamination concentration level. A user may enter a unique RPC mask using the format Waste type ${ }^{*}$ Handling ${ }^{*}$ TRU alpha*non-TRU alpha. The masking protocol also allows a user to use wildcards to make the mask less specific. For example, to select only mixed low-level waste, enter $L^{*}$ in the RPC mask list box. Entering this mask will cause the report to include only mixed low-level waste streams regardless of handling or alpha contamination.

The list box arrows to the right of each list box provides a list of RPC, MPC, and CPC example masks. A user may select any one of these as a mask for a report. The following lists of RPC, MPC, and CPC masks are provided under each list box arrow:

RPC Mask Waste Stream Report will only include

LL*CH* Low-level contact-handled

LL*RH* Low-level remote-handled

TR* $\mathrm{CH}^{*} \quad$ Transuranic contact-handled

TR*RH* Transuranic remote-handled

$\mathrm{LL}^{*} \mathrm{CH}^{*} \mathrm{~T} 11^{*}$ Low-level contact-handled TRU alpha $10-100 \mathrm{nCi} / \mathrm{g}$

$\mathrm{LL}^{*} \mathrm{CH}^{*} \mathrm{~T} 12 * \quad$ Low-level contact-handled TRU alpha $0-10 \mathrm{nCi} / \mathrm{g}$

$\mathrm{LL}^{*} \mathrm{CH}^{*} \mathrm{~T} 20^{*}$ Low-level contact-handled no TRU alpha

LL*CH*T90* Low-level contact-handled TRU alpha level unknown

$\mathrm{LL}^{*} \mathrm{CH}^{*} \mathrm{~N} 11$ Low-level contact-handled non-TRU alpha $>10 \mathrm{nCi} / \mathrm{g}$

MPC Mask Waste Stream Report will only include

L1* Aqueous liquids/slurries

L2* Organic liquids

S3* Homogeneous solids

S4* Soil/gravel

S5* Debris waste

X6* Lab packs

$\mathrm{X} 7^{*} \quad$ Special wastes

X72* Elemental hazardous materials

X721* Elemental lead

CPC Mask Waste Stream Report will only include

RC*O11* RCRA Organics

RC*O90* RCRA No organics

RC*M11* RCRA Metals w/o mercury 


$\begin{array}{ll}\mathrm{RC}^{*} \mathrm{M} 12^{*} & \text { RCRA Metals w/mercury } \\ \mathrm{RC}^{*} \mathrm{C} 11 & \text { RCRA Ignitable } \\ \mathrm{RC}^{*} \mathrm{C} 12 & \text { RCRA Corrosive } \\ \mathrm{RC}^{*} \mathrm{C} 13 & \text { RCRA Reactive } \\ \mathrm{RC}^{*} \mathrm{O} 11^{*} \mathrm{M} 11^{*} & \text { RCRA Organics and metals w/o mercury }\end{array}$

A user may develop a mask for any or all of the list boxes provided. An MPC mask can be developed using any portion of a DOE Treatability Group Guidance matrix code. A CPC mask can be developed using the format Regulatory classification*Organics*Metals*Ignitable/ Corrosive/Reactive.

The Ordering radio buttons allow a user to place a primary sort on certain fields in the report To have the report sorted by waste stream identification number, RPC, MPC, CPC, inventory value, or projection value. The report generator does not allow secondary or tertiary sorting. An alternative to secondary and tertiary sorting is applying a more specific RPC, MPC, or CPC mask to narrow down the number of records provided in the report. This may require more than one report.

The Print to Screen (the icon with a sheet of paper and a magnifying glass) button allows the user to review the report before sending it to the printer. Completing this step before printing is highly recommended. After selecting the button, the user will see an on-screen version of the report. For a complete discussion of Printing Options, see the end of Section 7.4.1.

\subsubsection{Treatment System Summary Report Options.}

The treatment system report generator is intended to provide a specific report for one or more individual treatment systems. The user enters the Treatment System Summary Report Options screen by selecting Treatment System from the pull-down menu from the Report selection on the Menu Bar. The Treatment System Summary Report Options screen is shown in Figure 7-5.

The Treatment System Summary Report provides the treatment system identification number, treatment system name, facility status, treatment technology, acceptable radiological waste types, acceptable RPC codes, acceptable MPC codes, acceptable CPC codes, and the scale of the treatment facility for each treatment system survey associated with a particular DOE Operations Office, state hosting DOE facilities, or DOE site. After entering the Treatment System Summary Report Options screen, the user can print the Treatment System Summary Report by following these steps:

- Highlight the appropriate Ops Office, State, Site, or waste type from the list boxes on the left hand side of the window.

- Select either the Status, Technology, RPC Mask, MPC Mask, CPC Mask or TS Scale Mask, if desired, from the list boxes in the upper right hand portion of the window. These list boxes allow the user to specify general or distinct categories of treatment systems for inclusion in the report.

- Select one radio button to determine how the user would like the waste streams ordered in the report. The user can have them sorted by treatment system identification number, treatment system name, or treatment system status. 
- Select the Print to the Printer (the printer icon) or the Print to Screen (the icon with a sheet of paper and a magnifying glass) button. It is recommended that the user print to screen and review the report before sending the report to the printer.

- Select the Print the Treatment System Summary Report button.

- Select the Close Window (the icon with a closing door and an arrow) button to exit the Treatment System Summary Report Options screen.

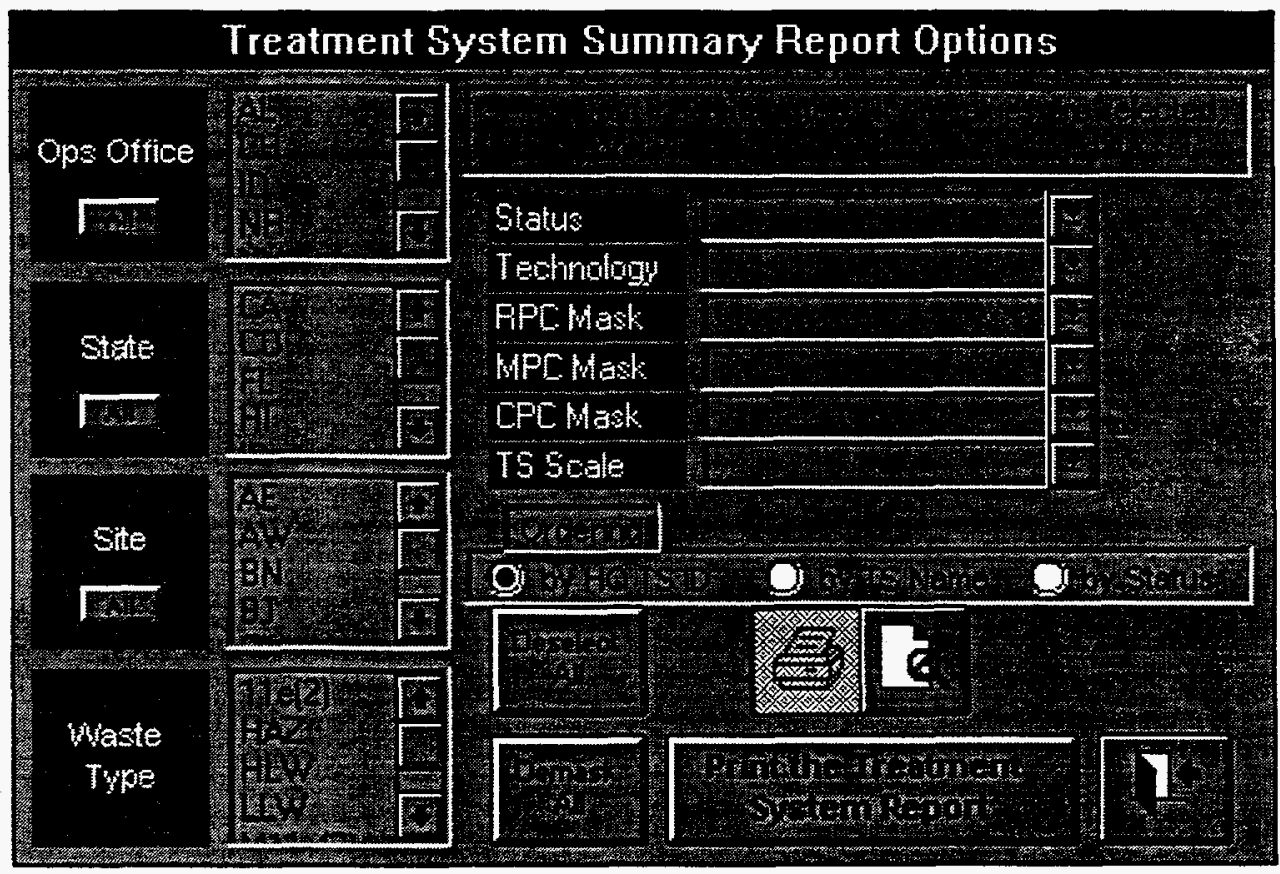

Figure 7-5. Treatment System Summary Report Options screen.

The Ops Office, State, Site, and Waste Type are hierarchial in the order Ops Office, State, Site, and Waste Type. This means that selecting a particular Ops Office will allow the user to only select host states, and DOE sites associated with that Ops Office. By selecting a particular Ops Office and a particular host state, the user will only be allowed to select DOE sites that meet both criteria. The user may select all DOE Ops Offices, States, or Sites by selecting the All button for any of the list boxes. The user may select one Ops Office, one State, and use the All button to select all Sites under that Operations office and host state. Please note that selecting a particular Waste Type provides different results than in the Waste Stream Report. Selecting a waste type in the Treatment System Summary Report will provide all the treatment systems that will accept that waste type, but may also accept other waste types. The user may deselect all Ops Office, State, Site, and Waste Type selections by selecting the Deselect All button in the middle of the window. 
The Status Mask, Technology Mask, RPC Mask, MPC Mask, CPC Mask, and TS Scale Mask list boxes allow the user to be very selective regarding which types of treatment systems listed in the report. The Status Mask allows the user to identify groups of treatment systems that are currently operating, under construction, being designed, or are no longer operational. Some treatment systems are no longer being reported and are designated as "Removed from MWIR." The following is the complete list of treatment system status masks that can be used in the report generator. The list is also provided under the list box arrow to the right of the list box.

\author{
Status Mask \\ Construction Complete \\ Funded: Conceptual \\ Funded: Other (specify) \\ Funded: Title I \\ Funded: Title II \\ Non-Operational \\ Operating \\ Other (specify) \\ Planned \\ Removed from MWIR \\ Under Construction
}

The Technology Mask allows the user to identify groups of treatment systems that have similar technologies. The technology mask allows selection of a wide range of responses from general technology categories to very specific technologies. The complete list of technology status masks can be found in the MWIR-1995 data dictionary (TRT_TECH_LU instructions and harcopy). The following list is a sample of the technology masks that can be used in the report generator and is also provided under the list box arrow to the right of the list box.

\begin{tabular}{|c|c|}
\hline Technology ID\# & Technology \\
\hline $4.2 .1^{*}$ & DESTRUCTION technologies \\
\hline 4.2.1.1* & General Organic Destruction Technologies \\
\hline 4.2.1.1.3* & Thermal Treatment Technologies \\
\hline 4.2.1.1.3.3* & Incineration Technologies \\
\hline 4.2.1.1.3.3.5 & Rotary Kiln Incineration \\
\hline $4.2 .2^{*}$ & REMOVAL technologies \\
\hline $4.2 .3^{*}$ & IMMOBILIZATION technologies \\
\hline $4.2 .4^{*}$ & DEACTIVATION technologies \\
\hline $4.2 .5^{*}$ & OTHER TREATMENT technologies \\
\hline $4.2 .6^{*}$ & NOT DETERMINED technologies \\
\hline
\end{tabular}

The RPC Mask, MPC Mask, and CPC Mask codes can be found in the DOE Treatability Group Guidance (DOE/LLW-217 Rev. 0). Refer to section 7.4.1, Waste Type Report Options, for a discussion on RPC, CPC, and MPC masking. The TS Mask allows the user to identify groups of treatment systems that have similar scale. The treatment system scale mask provides a general indication of the size of a particular treatment system. The following is the complete list of treatment system status masks that can be used in the report generator. The list is also provided under the list box arrow to the right of the list box. 


\section{Treatment Scale \\ Bench Scale \\ Demonstration or Pilot-Plant Scale \\ Full-Size Plant Scale \\ Portable Scale}

The Ordering radio buttons allow the user to have the report sorted by treatment system identification number, treatment system name, or treatment system status. The report generator does not allow secondary or tertiary sorting. An alternative to secondary and tertiary sorting is applying more specific masks which allow the user to narrow down the number of records provided in the report. This may require that the user generate more than one report, but the user should be able to produce the categories needed.

The Print to Screen (the icon with a sheet of paper and a magnifying glass) button allows the user to review the report before sending it to the printer. Completing this step before printing is highly recommended so the user can review the report and ensure that the user will receive the information anticipated. After selecting the button, the user will be taken to an on-screen version of the report. For a complete discussion of printing options, see the end of Section 7.4.1.

\subsection{Printing the MWIR-1995 Data Dictionary}

The MWIR-1995 report feature allows the user to print a copy of the data dictionary of the system. The data dictionary includes the name, type, size, and description of each field in every table within the system. The data dictionary lists the table names and field names in alphabetical order. The user can print the data dictionary by selecting Data Dictionary from the pull-down menu from the Report selection on the Menu Bar followed by Print. The user can print the data dictionary to file by selecting Data Dictionary from the pull-down menu from the Report selection on the Menu Bar followed by Print to File. Printing to file allows the user to export the data dictionary as a Microsoft Excel 3.0 file (*.xls), a Rich Text Format file (*.rtf), or an MS-DOS Text file (*.txt). The file will be located in the MWIR-1995 directory unless otherwise specified. 


\section{EDITING/UPDATING DATA}

MWIR-1995 has several features that provide for editing and updating data. The majority of those features are disabled if MWIR-1995 is attached to "read only" data (see section 4.1, Entry into MWIR-1995, for information on how to determine if the user is connected to "read only" data). The following sections describe large scale features associated with editing and updating data. All of the following features, except for Spell Checking, are disabled for "read only" data.

\subsection{Create Survey}

Create Survey is used when a completely new survey is being added to MWIR-1995 and the information is completely new. If the information is essentially the same as an existing survey, then Duplicate Survey may be a better choice.

1. From the Main Menu select DOE Site for the survey to be created.

2. Click the list box arrow.

3. Select the DOE site: the user will be at the first screen of the new survey and the SURVEY_ACTIONS table will be updated with the new survey id, action (created), action date, action time, and comment (MITI-95).

\subsection{Delete Survey}

Delete survey is used when the survey should be removed from MWIR-1995 (i.e., the survey was entered in error or the survey does not have a valid DOE-HQ ID). Delete survey should not be used when the entire inventory of a waste stream has been removed from the site or has been completely recharacterized into other waste streams. In these cases the waste stream is dispositioned in Section 2 of the survey (Section 2.2.2 or 2.2.3). To delete a survey, perform the following steps:

1. From the Main Menu select Survey to be Duplicated/Deleted.

2. Click the list box arrow.

3. Select the survey to be deleted.

4. Click Delete Survey: a dialog box will appear indicating the survey to be deleted and requesting a reason for deletion.

5. Enter the reason for deletion: this should be short but descriptive (e.g., this survey renumbered to PX-W028).

6. Select $\mathrm{OK}$ or press enter: the survey will be deleted from the database and the SURVEY_ACTIONS table will be updated with the survey ID, action (deleted), action date, action time, and comment (reason for deletion). 


\subsection{Duplicate Survey}

Duplicate survey is used when a new survey is desired and the data is essentially the same or when the current survey does not have a valid DOE-HQ ID (e.g., RF-T001, RL-M001, SR-N001, IN-001A). To duplicate a survey, perform the following steps:

1. From the Main Menu select Survey to be Duplicated/Deleted.

2. Click the list box arrow.

3. Select the survey to be duplicated.

4. Click Duplicate Survey: a dialog box will appear -- Duplicating ... \% complete.

5. When the duplication is complete, the user will be at the first screen of the new survey and the SURVEY_ACTIONS table will be updated with the new survey ID, action (duplicated), action date, action time, and comment (e.g., this survey duplicated from $\mathrm{xx}-\mathrm{xxxx}$ ).

\subsection{Edit Survey}

Edit Survey takes the user to the first screen of the selected survey type. The user can then navigate to the survey ID and screen that contains the information that requires editing. The editing features available are a combination of Windows features and Microsoft Access features. Review Appendix A, Menu Bar, and Appendix B, Tool Bar for a quick review of available edit features.

1. From the Main Menu click the button for the desired survey type. The choices are Waste Stream or Treatment System.

2. Click the Edit Survey button; this will take the user to the first screen of the survey type selected.

\subsection{Spell Check}

Spell check can be used when in the Form mode or the Datasheet mode. It cannot be used when in Query Builder mode. Use spell check as follows:

1. Select the field to be checked.

2. From the toolbar select Spell Check; the spell checker will scan the field and compare each text item against the installed dictionaries (mainus.dic and private.dic); if no differences are noted, the cursor will move to the end of the field and no messages will be displayed.

3. If text is found that is not in the installed dictionaries, a dialog box will appear that displays the text, provides suggestions on possible replacements, and provides options on disposition of the text. 


\section{MWIR-1995 SUPPORT}

\subsection{Technical Support}

Personnel are available to answer questions about problems with computers, hardware, or software as they relate to MWIR-1995. Normal working hours are 8:00 am to 4:30 pm mountain time.

- Robert L. Devries, Project Manager

Radioactive Waste Technical Support

Phone: $208-526-2746$

Fax: 208-526-8878

E-Mail: rdx@inel.gov

Regular mail:

Lockheed Martin Idaho Technologies MS-2420

P.O. Box 1625

Idaho Falls, ID 83415-2420

Express mail:

Lockheed Martin Idaho Technologies MS-2420

2525 North Fremont

Idaho Falls, ID 83415-2420

- Richard J. Ahlstrom, System Administrator

Programmatic Software Development

Phone: 208-526-0428

Fax: 208-526-6493

E-Mail: rja@inel.gov

Regular mail:

Lockheed Martin Idaho Technologies MS-3209

P.O. Box 1625

Idaho Falls, ID 83415-3209

Express mail:

Lockheed Martin Idaho Technologies MS-3209

2525 North Fremont

Idaho Falls, ID 83415-3209 


\subsection{Data Support}

MWIR-1995 contains information on EM-30 waste streams, EM-40 waste streams, and mixed waste treatment systems. Personnel are available to answer questions about these topics.

EM-30 Sites

- Tim Kirkpatrick, Data Administrator

Radioactive Waste Technical Support

Phone: 301-903-1299

Fax: 301-903-1308

E-Mail: tk2@inel.gov

Regular mail:

Lockheed Martin Idaho Technologies

Trevion I, Room \#434

Germantown, MD 20874

Express mail:

Lockheed Martin Idaho Technologies

Trevion I, 4th Floor, Room \#434

Germantown, MD 20874

EM-40 Sites

- John M. Peterson, Nuclear Engineer

Environmental Assessment Division, ANL-E

Phone: 708-252-3183

Fax: 708-252-4336

E-Mail: petersoj@smtplink.ead.anl.gov

Regular mail:

Argonne National Laboratory - East

9700 South Cass Avenue, Bldg 900

Argonne, IL 60439

Express mail:

Argonne National Laboratory - East

1200 International Parkway

Woodridge, IL 60517 
Treatment Systems

- Wendy L. Carlson, Project Engineer

Radioactive Waste Technical Support

Phone: 208-526-6928

Fax: 208-526-8878

E-Mail: wcy@inel.gov

Regular mail:

Lockheed Martin Idaho Technologies MS-2420

PO Box 1625

Idaho Falls, ID 83415-2420

Express mail:

Lockheed Martin Idaho Technologies MS-2420

2525 North Fremont

Idaho Falls, ID 83415-2420 
Appendix A

MWIR-1995 Menu Bar 


\section{Appendix A}

\section{MWIR-1995 Menu Bar}

This appendix describes the Menu Bar (Figure A-1), which contains most of the functions of the Tool Bar, and includes other less used options. To select a menu item, click it with a mouse, or press the Alt key with the underlined letter of the option. When using the Query Builder, the Menu Bar can be used to manipulate queried data.

\section{File Edit Yiew Records Report Window Help}

Figure A-1. Menu Bar.

1. File

a. Close: Closes the current form. The current form will have its title bar highlighted. To retrieve the closed form select Next Page or Previous Page from the toolbar.

b. Save Record: Saves all changes to the current record (this action can also be accomplished by selecting a new record, selecting a new form, or selecting a new screen).

c. Output To...: Outputs the contents of the active object (form or datasheet) to a file with the extensions .xls (Microsoft Excel), .rtf (Rich Text Format), or .txt (MS-DOS text). Select the type of file to write to and press the OK button. Enter the file name and drive/path where the user wishes this file to be written, and press OK. This allows further manipulation of selected information using a spreadsheet program or a word processor.

d. Print Setup...: Displays the Windows Print Setup screen. This allows a user to alter any options before printing the active object.

e. Print Preview: Displays the active object in print preview mode (the way it would look if printed). Select print preview again to return the object to its original view.

f. Print ...: Displays the Windows Print dialog window. Press OK to print the active object.

NOTE: It is recommended that when printing to an HP LaserJet 3 printer, an HP LaserJet Series II printer be selected as the default printer. This will ensure correct operation of the print survey feature. Other printers perform correctly as long as the default printer matches the actual printer. 
g. Attach Data: Displays a screen titled Where is MITI95.MDB? This allows the user to identify the path and file name of the data to be used. This screen also provides a means of changing directories and drives, and of listing file types by a user-selected extension.

h. Export: Allows the user to export information from any of the tables contained in MWIR-1995 into a selected format (This is usually selected when the user wants to work with the data using another database program). Selectable formats include but are not limited to Microsoft Access, Excel, Lotus, Paradox, FoxPro, dBase, and Btrieve.

i. Exit: Closes all open forms, exits MWIR-1995, and returns the user to Windows.

2. $\quad$ Edit

a. Can't $\underline{\text { Undo/Undo }}(\mathrm{C} t r l+Z)$ : Reverts any changes recently made to the previous value contained in the field. If no changes have been made, the edit mode is Can't Undo.

b. Undo Current Field (Esc): This provides an opportunity for the user to undo changes to the current field/record prior to saving it to the database. This is only available while in the form where the changes are being made. Once another form is selected, the changes are committed and cannot be undone.

c. Cut $(\mathrm{Ctrl}+\mathrm{X})$ : Cuts or removes currently highlighted text (or record) and places it into the paste buffer.

d. Copy $(\mathrm{Ctrl}+\mathrm{C})$ : Copies the currently highlighted text (or record) into the paste buffer.

e. Paste (Ctrl+V): Adds, or inserts the contents of the paste buffer to the location of the cursor.

f. Delete: Deletes currently highlighted text or record.

g. Select Record: Selects the current record. Operations such as cut, copy, or delete can be performed on the current record. This may be used when the user wants to copy a desired record to more than one waste stream.

h. Select Alll Records: Selects all records. Operations such as cut, copy, or delete can be performed on selected records. This may be used when the user wants to copy a desired group of records to more than one waste stream.

i. Find...: Displays the find dialog box, allowing the user to enter search criteria. Note: The asterisk $\left(^{*}\right)$ is the wildcard character.

j. $\quad$ Replace...: Displays the find/replace dialog box, allowing the user to make global text changes.

3. View: Allows the user to select whether an active form is viewed in "form" or "datasheet" format. 
a. Form: Displays the contents of the current datasheet in a form format.

b. Datasheet: Displays the contents of the current form in a datasheet format.

c. MITI Toolbar: Selecting this option will allow recovery of the toolbar, should the user inadvertently delete it.

4. Records

a. Go To

i. First: Moves pointer to the first record of the selected form.

ii. Last: Moves pointer to the last record of the selected form.

iii. Next: Moves pointer to the next record of the selected form.

iv. Previous: Moves pointer to the previous record of the selected form.

v. New: Moves the pointer to a new record of the selected form (a new record has no data entered in any of its fields).

b. Refresh: Commits any data changes and repaints the screen that is displayed.

c. Quick Sort

i. Ascending: Sorts a selected field from datasheet view in ascending order.

ii. Descending: Sorts a selected field from datasheet view in descending order.

d. Show All Records: Displays all records for the active form.

5. Report:

a. Data Dictionary

i. Print: Sends the MWIR-1995 data dictionary to be printed, via user-designated format, file name, and path, or

ii. $\quad$ Gutput to File: Outputs the data dictionary to any of three file formats listed. The file formats available are Microsoft Excel (*.xls), Rich Text Format (*.rtf), and MS-DOS Text (*.txt).

b. Print Survey: Displays a Print Survey Options screen where the user can select which survey(s) will be printed. 
By designating the applicable DOE Operations Office, the State, and the Site, the user can print a survey based on his selection. Other choices are a specific waste type, all surveys, all Treatment System (TS) surveys, or all Waste Stream (WS) surveys, or specific sections of surveys for WS, TS, and TRU surveys.

A selection for printing a "short" summary form, which allows the user to make a quick review to ensure that the information in the particular survey matches his data needs before taking the time to print an entire survey.

c. Waste Stream : Provides the user with options for two reports:

i. Waste Stream Reports: A window where a Waste Stream-Specific Report based on the criteria selected by the user can be viewed or printed. Criteria that can be specified by the user are Radiological Parameter Category (RPC), Matrix Parameter Category (MPC), Contaminant Parameter Category (CPC), DOE Operations Office (OPS Office), State, Site, and Waste Type. The user can order the output of the Waste Stream Report by selecting from the list of choices.

ii. Waste Type Reports: A window where a Waste Type Summary Report based on the criteria selected by the user can be viewed or printed. Criteria that can be specified by the user are DOE Operations Office (OPS Office), State, and Site. The user can specify the detail of the Waste Type Report by selecting from the list of choices; MPC Detail (a list of all reported MPCs), MPC Summary (a rolled up summary of the reported MPCs), or No MPC (Inventory only).

d. Treatment System: A window where a Treatment System Summary Report based on the criteria selected by the user can be viewed or printed. Criteria that can be specified by the user are DOE Operations Office (OPS Office), State, Site, Waste Type, Status, Technology, Radiological Parameter Category (RPC mask), Matrix Parameter Category (MPC mask), Contaminant Parameter Category (CPC mask), and Scale of the treatment systems (TS Scale). The user can order the output of the Treatment System Summary Report by selecting from the list of choices.

6. Window: Displays all forms currently opened in MWIR-1995. Click the form name to make it the active object.

\section{Help}

a. Contents: Provides the user with an on-screen table of contents for the MITI Help module.

b. Search...: Allows the user to select and transfer directly to a specific help topic within the Help module.

c. About MITI...: This selection brings up a window titled "About This System" where the producer and the system owner are identified. 
i. More...: The More button displays a dialog box that contains:

- Forms Version: The last date the MIT195 forms were revised (e.g., 10/25/95).

- Data Version: The last date the baseline data was revised (e.g., 10/25/95).

- Data File: Lists the complete path for the data file that is attached to MWIR1995 (e.g., c:lmitilmwirread.mdb). 
Appendix B

MWIR-1995 Tool Bar 


\section{Appendix B}

\section{MWIR-1995 Tool Bar}

This appendix describes the Tool Bar (Figure B-1) buttons that are available for all forms. Not all buttons work at all times (e.g., if nothing has been changed, the undo button will not be highlighted). When using Query Builder, the toolbar functions are generally disabled. The Menu Bar can be used to manipulate queried data.

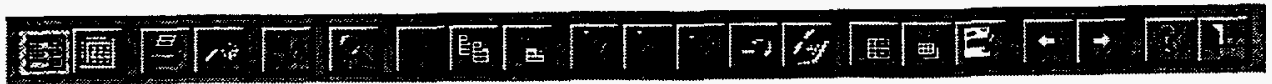

Figure B-1. Tool Bar.

1. Form View: Displays the contents of the current datasheet in a form format.

2. Datasheet View: Displays the contents of the current form in a datasheet format.

3. Print Survey: Displays a window where surveys can be printed based on the criteria selected by the user. The criteria are split into two categories: (a) What surveys to print and (b) What part of those surveys to print.

What surveys: Criteria that can be selected by the user are DOE Operations Office (OPS Office), State, Site, and Waste Type. The user can also specify all surveys, all Treatment System (TS) surveys, all Waste Stream (WS) surveys, or can select the specific surveys from the provided list.

What part of the selected surveys: The level of detail of the printed surveys can be selected by the user. The user can print a complete survey, a short survey, a part of a survey, or a specific section of a survey.

4. New: The new button opens a new (blank) record at the end of the current list of records. The user can also open a new record by pressing the last record and next record buttons on the Record Select Bar.

5. Save Record: The save record button commits all data, writing it out to the data file that is attached to MIT195 (this action can also be accomplished by selecting a new record, selecting a new form, or selecting a new screen).

6. Zoom In: The Zoom In button displays the text of the current field in a larger scrolling window. Changes can be made to the data in the zoomed window. A beep sounds when the amount of data entered in the zoom window equals the amount of data allowed by the

a. The short survey allows the user to make a quick review to assure the information in the particular survey matches data needs before taking the time to print an entire survey. 
database, for this field. The OK button displayed on the zoom window saves any changes, the cancel button reverts to the original value.

7. Cut: The cut (Ctrl-X) button cuts the highlighted text from the current field and places it into the paste buffer.

8. Copy: The copy (Ctrl-C) button copies the highlighted text from the current field and places it into the paste buffer.

9. Paste: The paste (Ctrl-V) button inserts the contents of the paste buffer into the location of the cursor in the current field.

10. Enter Query: The enter query button places the current form into query mode. This allows the user to enter search criteria that restrict the data returned form the query. The user can enter a search criteria in as many fields as are displayed. Leaving all fields blank returns all records (a blind query).

NOTE: The asterisk $\left(^{*}\right)$ is the wildcard operator.

11. Execute Query: The Execute Query button re-queries the current form to display all data that matches the search criteria and places the form back into edit mode.

12. Cancel Query: The Cancel Query button removes all search criteria, re-queries all data, and places the current form back into edit mode.

13. Undo: The Undo button cancels changes made to the current field. The escape key (Esc) also performs the undo function.

14. Undo Current Field/Record: The Undo Current Field/Record button cancels changes made to the current field or record.

15. Jump to Section: The Jump to Section button displays a form listing all sections of both treatment system and waste stream surveys. Double-click the desired section to jump to, or press the close door button to exit.

16. Query Builder: The Query Builder button displays a dialog box that contains the tables that can be used for building queries. The Query Builder steps through a process that results in the SQL statements necessary to return the information that meets the criteria established using the Query Builder.

17. Spell Check: The Spell Check button activates a routine that checks the spelling for text in the field that was active when spell check was selected.

18. Previous Page: The Previous Page button selects the previous page of the MWIR-1995 forms. Use the Jump to Section button to select the section of the survey to move to. 
19. Next Page: The Next Page button selects the next page of the MWIR-1995 forms. Use the Jump to Section button to select the section of the survey to move to.

20. F1 Help: The Help button displays the first page of context sensitive help. The user can scroll through the help or can select Contents or Search to more quickly arrive at the desired location.

a. Contents: Provides the user with an on-screen table of contents for the MITI Help module.

b. Search ...: Allows the user to select and transfer directly to a specific help topic within the Help module.

21. Close Window: The Close Window (Exit) button closes the current form. If the current form is the Main Menu, pressing this button exits MWIR-1995. 
Appendix C

MWIR-1995 Look-Up Tables 


\section{Appendix C}

\section{MWIR-1995 Look-Up Tables}

This appendix describes the look-up tables that have been provided for those data elements where consistent reporting is necessary or where the look-up table will simplify use of MWIR-1995.

Additional information about look-up tables and other tables in MWIR-1995 can be found in the Data Dictionary. The look-up tables that reside in MWIR-1995 are:

1. Contaminant Parameter Categories (CPC_LU): This look-up table contains the Treatability Group Regulated Contaminant Parameter Category Codes.
a. CPC_Code: Contaminant Parameter Categories..
b. CPC_Desc: Contaminant Parameter Categories description..

2. EPA Codes, LDR Codes, Contaminants, and descriptions (EPA_LU): This look-up table contains EPA/State codes.
a. EPA_Code: The EPA/State Code.
b. LDR_Code: The LDR Code.
c. Contam_Name: The contaminant (name) for the EPA code.
d. Comments: EPA/State code comments.

3. Matrix Parameter Categories (MPC_LU): This look-up table contains the Treatability Group Matrix Parameter Category Codes.
a. MPC_Code: The Matrix Code.
b. MPC_Name: The Name (description) of the Matrix Code.
c. Roll_Up_Code: The summary Matrix Code that this MPC_Code is assigned to with.

4. Treatment System Permits and related information (PERMIT_LU): This look-up table contains default permit information.
a. LawAct_Code: Acronym for the Law or Act requiring a permit (e.g., CAA, NESHAP, NPDES, RCRA, or TSCA).
b. LawAct_Desc: The full name of the Law or Act requiring a permit.
c. Permit: The types of permits required by a specified Law or Act. 
d. Reference: The location of the text that discusses the permits associated with a specified Law or Act.

5. Treatment System Permit Status (PERMIT_STATUS_LU): This look-up table contains default permit status.

a. Status: A listing of the terms that describe the allowable status of a permit required by a specified Law or Act.

6. Radionuclides (RADIONUCLIDE_LU): This look-up table contains a list of radionuclides and related information.

a. Radionuclide: The identifier for a specific radioisotope.

b. Atomic_Number: The atomic number of the isotope.

c. Transuranium: Is this radionuclide transuranium? $(\mathrm{Y}, \mathrm{N})$.

d. Alpha_Emitter: Is this radionuclide an alpha emitter? $(\mathrm{Y}, \mathrm{N}, \mathrm{X})(\mathrm{X}=$ Not Applicable).

e. Half_Life_>20: Is the half life of this radionuclide greater than 20 years? $(\mathrm{Y}, \mathrm{N}, \mathrm{X})$ $(\mathrm{X}=$ Not Applicable).

f. Half_Life_Units: The units for the half life value $(Y, D, H, M, S)(Y=$ Years, $D=$ Days, $\mathrm{H}=$ Hours, $\mathrm{M}=$ Minutes, $\mathrm{S}=$ Seconds).

g. Half_Life_Value: The numeric value of the half life $(9.999 \mathrm{E} 99=$ Stable $)$.

h. Radionuclide_Name: The name of the radionuclide.

7. Radiological Parameter Categories (RPC_LU): This look-up table contains the Treatability Group Radiological Parameter Category Codes.

a. PRC_Code: The Treatability Group Radiological Parameter Category Code.

b. RPC_Desc: The description of the Treatability Group Radiological Parameter Category Code.

8. Site Names, Operations Offices, and States (SITE_LU): This look-up table contains the list of sites and operations offices and related information.

a. Site_Code: The two letter code that identifies a specific site.

b. Site_Name: The full name of the site.

c. Ops_Code: The two letter code of the operations office responsible for the site. 

d. Ops_Name: The full name of the operation office.
e. State: The State where the site resides.

9. Treatment System status (TRT_SYS_STATUS_LU): This look-up table contains allowable system status'.
a. System_Status: Status' allowed for a treatment system.

10. Treatment System Technologies (TRT_TECH_LU): This look-up table contains the list of treatment technologies.
a. Proc_Id: Process ID used to order the technologies list.
b. Tech_Label: A numeric label for each technology (i.e., 4.2.1.1.2).
c. Technology: The name of a specific technology

11. Transuranic Waste Final Waste Forms (TRU_FWF_LU): This look-up table contains the final waste form group.

a. FinalWasteForm: The final waste form group.

12. Transuranic Waste Shipping Container Types (TRU_SHIP_CONTAINER_LU): This lookup table contains the WTWBIR Shipping containers.
a. Ship_Container: The container type that will be used to ship the final form of this waste stream.

13. Transuranic Waste Container Materials (TRU_MATERIAL_LU): This look-up table contains container construction materials.
a. Material: The material used to construct containers.
b. Ship_Only: Default materials used for some shipping containers.

14. Transuranic Waste Liner Types (TRU_LINER_LU): This look-up table contains the liner types found in containers.

a. Liner_Type: The liner type used in containers.

15. Transuranic Waste Liner Materials (TRU_LINER_MATERIAL_LU): This look-up table contains a list of materials used to line containers.

a. Liner_Material: The material used to line containers. 
16. Transuranic Waste Repack Reasons (TRU_REPACK_LU): This look-up table contains the reasons a waste stream may require repackaging.
a. Repack_Cause: Reason repackaging is required.
b. Flag: Identifies the driver causing repackaging $(T, W, B)(T=$ Trampac only, $W$ = WACv3 only, B = Both).
c. Preferred_Order: The preferred order of the look-up list.

17. Transuranic Waste Treatment Reasons (TRU_TREATMENT_LU): This look-up table contains the reasons a waste stream may require treatment.
a. Treatment_Cause: Reason treatment is required.
b. Preferred_Order: The preferred order of the look-up list.

18. Transuranic Waste Material Distributions (TRU_WEIGHTS_LU): This look-up table contains the material parameters distribution by weight.
a. Material_Parameter: The material parameter that has weight in the shipping container.
b. Preferred_Order: The preferred order of the look-up list.

19. Waste Stream Source Categories (WS_SOURCE_CATEGORY_LU): This look-up table contains the list of values that are valid source categories for a waste stream.
a. Source_Category: The source category for the waste stream.
b. Preferred_Order: The preferred order of the look-up list.

20. Waste Stream Storage Methods (WS_STORAGE_LU): This look-up table contains the methods used to store waste streams.
a. Storage: The storage method used.
b. Preferred_Order: The preferred order of the look-up list. 